\title{
Toward Catalytic, Enantioselective Chlorolactonization of 1,2-Disubstituted Styrenyl Carboxylic Acids
}

\author{
Scott E. Denmark*, Pavel Ryabchuk, Matthew T. Burk and Bradley B. Gilbert \\ Department of Chemistry, University of Illinois Urbana-Champaign, Urbana, IL 61801 \\ SUPPORTING INFORMATION
}

TABLE OF CONTENTS

PAGE

General Experimental

Literature Preparations

Chlorlactonizations

Lewis Base Survey

Chiral Lewis Base Survey

Chlorolactonization of Model Substrates

References

S16

NMR Spectra 


\section{General Experimental}

All reactions were performed in oven $\left(160^{\circ} \mathrm{C}\right)$ and/or flame-dried glassware under an atmosphere of dry argon unless otherwise noted. Reaction solvents dichloromethane, toluene, DMF and THF (HPLC grade) were dried by percolation through neutral alumina in a solvent dispensing system. 1,1,1,3,3,3-Hexafluoro-2-propanol was dried over $3 \AA$ molecular sieves. Deuterochloroform and deuterodichloromethane were dried over $4 \AA$ molecular sieves before use. Triethylamine and pyridine were distilled from $\mathrm{CaH}_{2}$.

ACS reagent grade ethyl acetate, dichloromethane and hexanes used for chromatography and recrystallization were purchased from Fisher. Column chromatography was performed using Merck grade 9385, $60 \AA$ A silica gel. Visualization was accomplished by UV light, potassium permanganate $\left(\mathrm{KMnO}_{4}\right)$ or iodine vapor. $\mathrm{R}_{f}$ values reported were measured using a $10 \times 2 \mathrm{~cm}$ TLC plate in a developing chamber containing the solvent system described. Analytical and preparative thin-layer chromatography was performed on Merck silica gel plates with F-254 indicator.

Dibutyl sulfide, diphenyl sulfide, 1,3-diphenylimidazolidine-2-thione, quinuclidine, diphenyl selenide, tosyl amide, 2,4,6-trimethylaniline, diphenyl phosphoramide, tetrabutylammonium iodide, tetrabutylammonium acetate were purchased from commercial suppliers and used without further purification. Triethylamine and pyridine were distilled from $\mathrm{CaH}_{2}$ prior to use.

${ }^{1} \mathrm{H}$ NMR, ${ }^{13} \mathrm{C}$ NMR spectra were recorded on 400 or $500 \mathrm{MHz}$ NMR spectrometers (400 or $\left.500 \mathrm{MHz},{ }^{1} \mathrm{H} ; 126 \mathrm{MHz},{ }^{13} \mathrm{C}\right)$. Spectra were referenced to residual $\mathrm{CHCl}_{3}\left(7.26 \mathrm{ppm}{ }^{1} \mathrm{H} ; 77.00\right.$ ppm $\left.{ }^{13} \mathrm{C}\right)$ or $\mathrm{CD}_{2} \mathrm{Cl}_{2}\left(5.32 \mathrm{ppm}{ }^{1} \mathrm{H} ; 54.24 \mathrm{ppm}{ }^{13} \mathrm{C}\right)$. Assignments were obtained by reference to COSY and HMQC correlations. Chemical shifts are reported in ppm, multiplicities are indicated 
by s (singlet), d (doublet), t (triplet), q (quartet), p (pentet), h (hextet), hep (heptet), m (multiplet) and br (broad). Coupling constants, $J$, are reported in Hertz. EI and ESI mass spectra mass spectral data are reported in the form of $(\mathrm{m} / \mathrm{z})$ versus intensity. Infrared spectra (IR) were using ATR and peaks are reported in $\mathrm{cm}^{-1}$ with indicated relative intensities: s (strong, 67-100\%); $\mathrm{m}$ (medium, 34-66\%); w (weak, 0-33\%). Melting points (mp) were determined in sealed tubes and are corrected. Analytical supercritical fluid chromatography was performed with spectrophotometric detection at $220 \mathrm{~nm}$ using Daicel Chiralpak OD and AS columns. Analytical gas chromatography was performed using 30-m Astec G TA or B PH (ChiraldexTM) columns. Analytical high performance liquid chromatography (HPLC) was performed using a built-in photometric detector $(220 \mathrm{~nm}, 254 \mathrm{~nm})$. Chiral separations were performed using a Chirapak ® AD column.

\section{Literature Preparations}

(E)-5-Phenyl-4-pentenoic acid $\mathbf{8}$ was prepared by Claisen rearrangement according to the procedure of Gao and co-workers. ${ }^{1}$ 4-phenylpent-4-enoic acid was prepared by Wittig reaction according to the procedure of Borhan and co-workers. ${ }^{2}$ Dibutyl selenide, ${ }^{3} \mathrm{Cy}_{3} \mathrm{P}=\mathrm{S},{ }^{4} \mathrm{Bu}_{3} \mathrm{P}=\mathrm{S},{ }^{5}$ $\left(\mathrm{Me}_{2} \mathrm{~N}\right)_{3} \mathrm{P}=\mathrm{S}^{6}, \mathrm{Bu}_{3} \mathrm{P}=\mathrm{Se}^{7},\left(\mathrm{Me}_{2} \mathrm{~N}\right)_{3} \mathrm{P}=\mathrm{Se}^{7}$ were prepared by reaction of their parent phosphines with elemental $\mathrm{S}$ or $\mathrm{Se}$ according to the procedures specified. 1-Chlorobenzatriazole was prepared according the procedure of Cava and co-workers. ${ }^{8}$

\section{Chlorolactonizations}

\section{Lewis Base Survey.}

General procedure (Table 1). An 5-mm, oven-dried NMR tube equipped with a septum was charged with chlorinating agent $(0.24 \mathrm{mmol}, 1.2$ equiv) and then the tube was purged with 
Ar through a needle. Deuterochloroform (with $1 \% \mathrm{v} / \mathrm{v}$ TMS) $(1.0 \mathrm{~mL})$ was added via syringe and then the tube was agitated with a vortex mixer. $8(35.2 \mathrm{mg}, 0.2 \mathrm{mmol}, 1.0$ equiv) was added as a solid and then the tube was agitated with a vortex mixer. The reaction mixture was analyzed by ${ }^{1} \mathrm{H}$ NMR spectroscopy and then a Lewis base was added and then the tube was agitated with a vortex mixer. The reaction mixture was analyzed by ${ }^{1} \mathrm{H}$ NMR spectroscopy after $20 \mathrm{~h}$. Conversion of $\mathbf{8}$ and yields of $\mathbf{9}$ and respectively were calculated by comparing the integrated area of the signal of tetramethylsilane standard $(\delta 0.0(\mathrm{~s}, 12 \mathrm{H}))$ with the signal for $\mathrm{H}-6$ of $9(\delta$ $5.49(\mathrm{~d}, \mathrm{~J}=5.8 \mathrm{~Hz}, 1 \mathrm{H}))$ and $\mathrm{H}-5$ of $9(\delta 6.45(\mathrm{~d}, \mathrm{~J}=15.8 \mathrm{~Hz}, 1 \mathrm{H}))$.

\section{Table 1, Entry 5}

According to General Procedure, an NMR tube was charged with NCS (31.7 mg, 0.24 mmol, 1.2 equiv), $\mathrm{CDCl}_{3}(1.0 \mathrm{~mL})$ and $\mathbf{8}\left(35.2 \mathrm{mg}, 0.2 \mathrm{mmol}, 1.0\right.$ equiv) and $\left(\mathrm{Me}_{2} \mathrm{~N}\right)_{3} \mathrm{P}=\mathrm{S}(3.9$ mg, 0.02 mmol, 0.1 equiv). Yield of $30 \%$ was observed by ${ }^{1} \mathrm{H}$ NMR spectroscopy after $20 \mathrm{~h}$.

\section{Table 1, Entry 6}

According to General Procedure, an NMR tube was charged with NCS (31.7 mg, 0.24 mmol, 1.2 equiv), $\mathrm{CDCl}_{3}(1.0 \mathrm{~mL})$ and $\mathbf{8}\left(35.2 \mathrm{mg}, 0.2 \mathrm{mmol}, 1.0\right.$ equiv) and $\mathrm{Ph}_{3} \mathrm{P}=\mathrm{S}(5.9 \mathrm{mg}$, $0.02 \mathrm{mmol}, 0.1$ equiv). Yield of $23 \%$ was observed by ${ }^{1} \mathrm{H}$ NMR spectroscopy after $20 \mathrm{~h}$.

\section{Table 1, Entry 7}

According to General Procedure, an NMR tube was charged with NCS (31.7 mg, 0.24 mmol, 1.2 equiv), $\mathrm{CDCl}_{3}(1.0 \mathrm{~mL})$ and $\mathbf{8}\left(35.2 \mathrm{mg}, 0.2 \mathrm{mmol}, 1.0\right.$ equiv) and $\mathrm{Bu}_{3} \mathrm{P}=\mathrm{S}(4.7 \mathrm{mg}$, $0.02 \mathrm{mmol}, 0.1$ equiv). Yield of $21 \%$ was observed by ${ }^{1} \mathrm{H}$ NMR spectroscopy after $20 \mathrm{~h}$.

\section{Table 1, Entry 8}

According to General Procedure, an NMR tube was charged with NCS (31.7 mg, 0.24 mmol, 1.2 equiv), $\mathrm{CDCl}_{3}(1.0 \mathrm{~mL})$ and $\mathbf{8}\left(35.2 \mathrm{mg}, 0.2 \mathrm{mmol}, 1.0\right.$ equiv) and $\left(\mathrm{Me}_{2} \mathrm{~N}\right)_{2} \mathrm{C}=\mathrm{S}(2.6$ 
mg, 0.02 mmol, 0.1 equiv). Yield of $29 \%$ was observed by ${ }^{1} \mathrm{H}$ NMR spectroscopy after $20 \mathrm{~h}$.

\section{Table 1, Entry 9}

According to General Procedure, an NMR tube was charged with NCS (31.7 mg, 0.24 mmol, 1.2 equiv), $\mathrm{CDCl}_{3}(1.0 \mathrm{~mL})$ and 8 (35.2 $\mathrm{mg}, 0.2 \mathrm{mmol}, 1.0$ equiv) and 1,3diphenylimidazolidine-2-thione $(5.1 \mathrm{mg}, 0.02 \mathrm{mmol}, 0.1$ equiv). Yield of $25 \%$ was observed by ${ }^{1} \mathrm{H}$ NMR spectroscopy after $20 \mathrm{~h}$.

\section{Table 1, Entry 10}

According to General Procedure, an NMR tube was charged with NCS (31.7 mg, 0.24 mmol, 1.2 equiv), $\mathrm{CDCl}_{3}(1.0 \mathrm{~mL})$ and $8\left(35.2 \mathrm{mg}, 0.2 \mathrm{mmol}, 1.0 \text { equiv) and 1,3-( } \mathrm{Me}_{2} \mathrm{~N}\right)_{3} \mathrm{P}=\mathrm{Se}$ (4.9 mg, $0.02 \mathrm{mmol}, 0.1$ equiv). Yield of $25 \%$ was observed by ${ }^{1} \mathrm{H}$ NMR spectroscopy after $20 \mathrm{~h}$.

\section{Table 1, Entry 11}

According to General Procedure, an NMR tube was charged with NCS (31.7 mg, 0.24 mmol, 1.2 equiv), $\mathrm{CDCl}_{3}(1.0 \mathrm{~mL})$ and $\mathbf{8}\left(35.2 \mathrm{mg}, 0.2 \mathrm{mmol}, 1.0\right.$ equiv) and $\mathrm{Cy}_{3} \mathrm{P}=\mathrm{Se}(7.2 \mathrm{mg}$, $0.02 \mathrm{mmol}, 0.1$ equiv). Yield of $22 \%$ was observed by ${ }^{1} \mathrm{H}$ NMR spectroscopy after $20 \mathrm{~h}$.

\section{Table 1, Entry 12}

According to General Procedure, an NMR tube was charged with NCS $(31.7 \mathrm{mg}, 0.24$ mmol, 1.2 equiv), $\mathrm{CDCl}_{3}(1.0 \mathrm{~mL})$ and $\mathbf{8}\left(35.2 \mathrm{mg}, 0.2 \mathrm{mmol}, 1.0\right.$ equiv) and $\mathrm{Ph}_{2} \mathrm{Se}(4.6 \mathrm{mg}, 0.02$ mmol, 0.1 equiv). Yield of $0 \%$ was observed by ${ }^{1} \mathrm{H}$ NMR spectroscopy after $20 \mathrm{~h}$.

\section{Table 1, Entry 13}

According to General Procedure, an NMR tube was charged with NCS (31.7 mg, 0.24 mmol, 1.2 equiv), $\mathrm{CDCl}_{3}(1.0 \mathrm{~mL})$ and $\mathbf{8}\left(35.2 \mathrm{mg}, 0.2 \mathrm{mmol}, 1.0\right.$ equiv) and $\mathrm{Bu}_{2} \mathrm{Se}(3.9 \mathrm{mg}$, $0.02 \mathrm{mmol}, 0.1$ equiv). Yield of $0 \%$ was observed by ${ }^{1} \mathrm{H}$ NMR spectroscopy after $20 \mathrm{~h}$.

\section{Table 1, Entry 14}


According to General Procedure, an NMR tube was charged with NCS (31.7 mg, 0.24 mmol, 1.2 equiv), $\mathrm{CDCl}_{3}(1.0 \mathrm{~mL})$ and $\mathbf{8}\left(35.2 \mathrm{mg}, 0.2 \mathrm{mmol}, 1.0\right.$ equiv) and $\mathrm{Bu}_{2} \mathrm{~S}(2.9 \mathrm{mg}, 0.02$ mmol, 0.1 equiv). Yield of $38 \%$ was observed by ${ }^{1} \mathrm{H}$ NMR spectroscopy after $20 \mathrm{~h}$.

\section{Table 1, Entry 15}

According to General Procedure, an NMR tube was charged with NCS (31.7 mg, 0.24 mmol, 1.2 equiv), $\mathrm{CDCl}_{3}(1.0 \mathrm{~mL})$ and $8\left(35.2 \mathrm{mg}, 0.2 \mathrm{mmol}, 1.0\right.$ equiv) and $\mathrm{Ph}_{2} \mathrm{~S}(3.7 \mathrm{mg}, 0.02$ mmol, 0.1 equiv). Yield of $13 \%$ was observed by ${ }^{1} \mathrm{H}$ NMR spectroscopy after $20 \mathrm{~h}$.

\section{Table 1, Entry 16}

According to General Procedure, an NMR tube was charged with NCS $(31.7 \mathrm{mg}, 0.24$ mmol, 1.2 equiv), $\mathrm{CDCl}_{3}(1.0 \mathrm{~mL})$ and $8(35.2 \mathrm{mg}, 0.2 \mathrm{mmol}, 1.0$ equiv) and 2,4,6-trimethyl aniline (2.7 mg, 0.02 mmol, 0.1 equiv). Yield of 5\% was observed by ${ }^{1} \mathrm{H}$ NMR spectroscopy after $20 \mathrm{~h}$.

\section{Table 1, Entry 17}

According to General Procedure, an NMR tube was charged with NCS (31.7 mg, 0.24 mmol, 1.2 equiv), $\mathrm{CDCl}_{3}(1.0 \mathrm{~mL})$ and $\mathbf{8}\left(35.2 \mathrm{mg}, 0.2 \mathrm{mmol}, 1.0\right.$ equiv) and $\mathrm{TsNH}_{2}(3.4 \mathrm{mg}$, $0.02 \mathrm{mmol}, 0.1$ equiv). Yield of $0 \%$ was observed by ${ }^{1} \mathrm{H}$ NMR spectroscopy after $20 \mathrm{~h}$.

\section{Table 1, Entry 18}

According to General Procedure, an NMR tube was charged with NCS (31.7 mg, 0.24 mmol, 1.2 equiv), $\mathrm{CDCl}_{3}(1.0 \mathrm{~mL})$ and $8(35.2 \mathrm{mg}, 0.2 \mathrm{mmol}, 1.0$ equiv) and diphenyl phosphoramide (5.0 mg, $0.02 \mathrm{mmol}, 0.1$ equiv). Yield of $0 \%$ was observed by ${ }^{1} \mathrm{H}$ NMR spectroscopy after $20 \mathrm{~h}$.

\section{Table 1, Entry 19}

According to General Procedure, an NMR tube was charged with NCS (31.7 mg, 0.24 
mmol, 1.2 equiv), $\mathrm{CDCl}_{3}(1.0 \mathrm{~mL})$ and $\mathbf{8}(35.2 \mathrm{mg}, 0.2 \mathrm{mmol}, 1.0$ equiv) and quinuclidine (2.2 mg, 0.02 mmol, 0.1 equiv). Yield of $45 \%$ was observed by ${ }^{1} \mathrm{H}$ NMR spectroscopy after $20 \mathrm{~h}$.

\section{Table 1, Entry 20}

According to General Procedure, an NMR tube was charged with NCP (43.6 mg, 0.24 mmol, 1.2 equiv), $\mathrm{CDCl}_{3}(1.0 \mathrm{~mL})$ and $\mathbf{8}(35.2 \mathrm{mg}, 0.2 \mathrm{mmol}, 1.0$ equiv) and quinuclidine (2.2 mg, 0.02 mmol, 0.1 equiv). Yield of $72 \%$ was observed by ${ }^{1} \mathrm{H}$ NMR spectroscopy after $20 \mathrm{~h}$.

\section{Table 1, Entry 21}

According to General Procedure, an NMR tube was charged with DCDMH (47.3 mg, $0.24 \mathrm{mmol}, 1.2$ equiv), $\mathrm{CDCl}_{3}(1.0 \mathrm{~mL})$ and $\mathbf{8}(35.2 \mathrm{mg}, 0.2 \mathrm{mmol}, 1.0$ equiv) and quinuclidine (2.2 mg, 0.02 mmol, 0.1 equiv). Yield of $96 \%$ was observed by ${ }^{1} \mathrm{H}$ NMR spectroscopy after $20 \mathrm{~h}$.

\section{Table 1, Entry 22}

According to General Procedure, an NMR tube was charged with 1-CBT (36.8 mg, 0.24 mmol, 1.2 equiv), $\mathrm{CDCl}_{3}(1.0 \mathrm{~mL})$ and $\mathbf{8}(35.2 \mathrm{mg}, 0.2 \mathrm{mmol}, 1.0$ equiv) and quinuclidine (2.2 mg, $0.02 \mathrm{mmol}, 0.1$ equiv). Yield of $77 \%$ was observed by ${ }^{1} \mathrm{H}$ NMR spectroscopy after $20 \mathrm{~h}$.

\section{Chiral Lewis Base Survey}

General Procedure (Scheme 8): A 5-mm, oven-dried NMR tube equipped with a septum was charged with 1-CBT (10 mg, $0.078 \mathrm{mmol}, 1.2$ equiv) and 1,2,4,5- $\mathrm{C}_{6} \mathrm{H}_{2} \mathrm{Cl}_{4}(10.2 \mathrm{mg})$. The tube was then purged with Ar through a needle. Deuterochloroform (600 $\mu \mathrm{L})$ was added via syringe and then the tube was agitated with a vortex mixer. $8(12.1 \mathrm{mg}, 0.066 \mathrm{mmol})$ was added as a solid and then the tube was agitated with a vortex mixer. Solution of (DHQD) ${ }_{2}$ PHAL (5.0 mg in $50 \mu \mathrm{L}$ of $\mathrm{CDCl}_{3}, 0.0065 \mathrm{mmol}, 0.1$ equiv) was added via syringe and then the tube was agitated with a vortex mixer. The reaction mixture was analyzed by ${ }^{1} \mathrm{H}$ NMR spectroscopy after $1 \mathrm{~h}$ and $24 \mathrm{~h}$. After $24 \mathrm{~h}$, a solution of butyl vinyl ether in ethanol (15 vol\%, $100 \mu \mathrm{L})$ was added 
to quench the reaction. The resulting solution was concentrated in vacuo $\left(23{ }^{\circ} \mathrm{C}, 6 \mathrm{mmHg}\right)$. The residue was purified by column chromatography (silica gel $(1 \mathrm{~g}), 1 \mathrm{~cm}$ diam, hexane $/ \mathrm{CH}_{2} \mathrm{Cl}_{2}$, 20:80) to afford $8.8 \mathrm{mg}(66 \%)$ of $\mathbf{9}$ as a colorless oil.

SFC: $(5 R, 6 S) /(5 S, 6 R)-\mathbf{9}, \mathrm{t}_{\mathrm{R}} 7.0 \min (45.0 \%) ;(5 S, 6 R) /(5 R, 6 S)-\mathbf{9}, \mathrm{t}_{\mathrm{R}} 11.5 \min (55.0 \%)$; (Chirapak $\mathrm{AD}, 125$ bar, $3 \mathrm{~mL} / \mathrm{min}, 5 \% \mathrm{MeOH}$ in $\mathrm{CO}_{2}$ ).

\section{Chlorolactonization of 8 with 1-CBT in the presence of Nicotine.}

According to General Procedure, an NMR tube was charged with 1-CBT (12 mg, 0.078 mmol , 1.2 equiv), 1,2,4,5- $\mathrm{C}_{6} \mathrm{H}_{2} \mathrm{Cl}_{2}(11.1 \mathrm{mg}), \mathrm{CDCl}_{3}(600 \mu \mathrm{L}), 8$ (11.2 mg, $\left.0.066 \mathrm{mmol}\right)$, and Nicotine (1.0 $\mu \mathrm{L} 0.0065$ mmol, 0.1 equiv). A yield of $39 \%$ was observed by ${ }^{1} \mathrm{H}$ NMR spectroscopy after $24 \mathrm{~h}$. The reaction was quenched after $24 \mathrm{~h}$ to afford after chromatography (silica gel (1 g), $\left.\mathrm{CH}_{2} \mathrm{Cl}_{2}\right) 6.5 \mathrm{mg}(45 \%)$ of 9 .

SFC: $(5 R, 6 S) /(5 S, 6 R) \mathbf{- 9}, \mathrm{t}_{\mathrm{R}} 7.0 \min (49.6 \%) ;(5 S, 6 R) /(5 R, 6 S) \mathbf{- 9}, \mathrm{t}_{\mathrm{R}} 11.5 \min (50.4 \%)$; (Chirapak $\mathrm{AD}, 125$ bar, $3 \mathrm{~mL} / \mathrm{min}, 5 \% \mathrm{MeOH}$ in $\mathrm{CO}_{2}$ ).

\section{Chlorolactonization of 8 with 1-CBT in the presence of Dihydrocinchonidine.}

According to General Procedure, an NMR tube was charged with 1-CBT (12 mg, 0.078 mmol , 1.2 equiv), 1,2,4,5- $\mathrm{C}_{6} \mathrm{H}_{2} \mathrm{Cl}_{2}(11.1 \mathrm{mg}), \mathrm{CDCl}_{3}(600 \mu \mathrm{L}), 8(11.2 \mathrm{mg}, 0.066 \mathrm{mmol})$, and a suspension of dihydrocinchonidine $\left(1.9 \mathrm{mg}\right.$ in $150 \mu \mathrm{L}$ of $\mathrm{CDCl}_{3}, 0.0065 \mathrm{mmol}, 0.1$ equiv). A yield of $93 \%$ was observed by ${ }^{1} \mathrm{H}$ NMR spectroscopy after $26 \mathrm{~h}$. The reaction was quenched after $26 \mathrm{~h}$ to afford after chromatography (silica gel $\left.(1 \mathrm{~g}), \mathrm{CH}_{2} \mathrm{Cl}_{2}\right) 11.9 \mathrm{mg}(89 \%)$ of 9.

SFC: $(5 R, 6 S) /(5 S, 6 R)-\mathbf{9}, \mathrm{t}_{\mathrm{R}} 7.0 \min (48.0 \%) ;(5 S, 6 R) /(5 R, 6 S)-\mathbf{9}, \mathrm{t}_{\mathrm{R}} 11.5 \min (52.0 \%)$; (Chirapak AD, 125 bar, $3 \mathrm{~mL} / \mathrm{min}, 5 \% \mathrm{MeOH}$ in $\mathrm{CO}_{2}$ ).

\section{Chlorolactonization of 8 with 1-CBT in the presence of Quinidine.}

According to General Procedure, an NMR tube was charged with 1-CBT (12 mg, 0.078 
mmol , 1.2 equiv), 1,2,4,5- $\mathrm{C}_{6} \mathrm{H}_{2} \mathrm{Cl}_{2}(11.1 \mathrm{mg}), \mathrm{CDCl}_{3}(600 \mu \mathrm{L}), \mathbf{8}(11.2 \mathrm{mg}, 0.066 \mathrm{mmol})$, and a solution of quinidine $\left(1.9 \mathrm{mg}\right.$ in $50 \mu \mathrm{L}$ of $\mathrm{CDCl}_{3}, 0.0065 \mathrm{mmol}, 0.1$ equiv). A yield of $87 \%$ was observed by ${ }^{1} \mathrm{H}$ NMR spectroscopy after $2 \mathrm{~h}$. The reaction was quenched after $3 \mathrm{~h}$ to afford after chromatography (silica gel $\left.(1 \mathrm{~g}), \mathrm{CH}_{2} \mathrm{Cl}_{2}\right) 10.5 \mathrm{mg}(77 \%)$ of 9.

SFC: $(5 R, 6 S) /(5 S, 6 R) \mathbf{- 9}, \mathrm{t}_{\mathrm{R}} 7.0 \min (48.8 \%) ;(5 S, 6 R) /(5 R, 6 S) \mathbf{- 9}, \mathrm{t}_{\mathrm{R}} 11.5 \min (51.2 \%)$; (Chirapak $\mathrm{AD}, 125 \mathrm{bar}, 3 \mathrm{~mL} / \mathrm{min}, 5 \% \mathrm{MeOH}$ in $\mathrm{CO}_{2}$ ).

\section{Chlorolactonization of 8 with 1-CBT in the presence of Cinchonine.}

According to General Procedure, an NMR tube was charged with 1-CBT (12 mg, 0.078 mmol , 1.2 equiv), 1,2,4,5- $\mathrm{C}_{6} \mathrm{H}_{2} \mathrm{Cl}_{2}(11.1 \mathrm{mg}), \mathrm{CDCl}_{3}(300 \mu \mathrm{L}), 8(11.2 \mathrm{mg}, 0.066 \mathrm{mmol})$, and a a suspension of cinchonine (1.9 mg in $300 \mu \mathrm{L}$ of $\mathrm{CDCl}_{3}, 0.0065 \mathrm{mmol}, 0.1$ equiv). A yield of $95 \%$ was observed by ${ }^{1} \mathrm{H}$ NMR spectroscopy after $0.8 \mathrm{~h}$. The reaction was quenched after $3 \mathrm{~h}$ to afford after chromatography (silica gel (1 g), $\left.\mathrm{CH}_{2} \mathrm{Cl}_{2}\right) 9.3 \mathrm{mg}(67 \%)$ of 9 .

SFC: $(5 R, 6 S) /(5 S, 6 R)-\mathbf{9}, \mathrm{t}_{\mathrm{R}} 7.0 \min (49.4 \%) ;(5 S, 6 R) /(5 R, 6 S) \mathbf{- 9}, \mathrm{t}_{\mathrm{R}} 11.5 \min (50.6 \%)$; (Chirapak AD, 125 bar, $3 \mathrm{~mL} / \mathrm{min}, 5 \% \mathrm{MeOH}$ in $\mathrm{CO}_{2}$ ).

\section{Chlorolactonization of 8 with 1-CBT in the presence of Quinine.}

According to General Procedure, an NMR tube was charged with 1-CBT (12 mg, 0.078 mmol , 1.2 equiv), 1,2,4,5- $\mathrm{C}_{6} \mathrm{H}_{2} \mathrm{Cl}_{2}(11.1 \mathrm{mg}), \mathrm{CDCl}_{3}(600 \mu \mathrm{L}), 8(11.2 \mathrm{mg}, 0.066 \mathrm{mmol})$, and a solution of quinine $\left(2.1 \mathrm{mg}\right.$ in $50 \mu \mathrm{L}$ of $\mathrm{CDCl}_{3}, 0.0065 \mathrm{mmol}, 0.1$ equiv). A yield of $82 \%$ was observed by ${ }^{1} \mathrm{H}$ NMR spectroscopy after $2 \mathrm{~h}$. The reaction was quenched after $2 \mathrm{~h}$ to afford after chromatography (silica gel ( $\left.1 \mathrm{~g}), \mathrm{CH}_{2} \mathrm{Cl}_{2}\right) 10.4 \mathrm{mg}$ (76\%) of 9.

SFC: $(5 R, 6 S) /(5 S, 6 R) \mathbf{- 9}, \mathrm{t}_{\mathrm{R}} 7.0 \min (49.4 \%) ;(5 S, 6 R) /(5 R, 6 S) \mathbf{- 9}, \mathrm{t}_{\mathrm{R}} 11.5 \min (50.6 \%)$; (Chirapak $\mathrm{AD}, 125 \mathrm{bar}, 3 \mathrm{~mL} / \mathrm{min}, 5 \% \mathrm{MeOH}$ in $\mathrm{CO}_{2}$ ). 


\section{Chlorolactonization of 8 with 1-CBT in the presence of Cinchonidine.}

According to General Procedure, an NMR tube was charged with 1-CBT (12 mg, 0.078 mmol , 1.2 equiv), 1,2,4,5- $\mathrm{C}_{6} \mathrm{H}_{2} \mathrm{Cl}_{2}(11.1 \mathrm{mg}), \mathrm{CDCl}_{3}(600 \mu \mathrm{L}), 8$ (11.2 mg, $\left.0.066 \mathrm{mmol}\right)$, and cinchonidine (1.9 mg, 0.0065 mmol, 0.1 equiv). A yield of $81 \%$ was observed by ${ }^{1} \mathrm{H}$ NMR spectroscopy after $2.2 \mathrm{~h}$. The reaction was quenched after $3 \mathrm{~h}$ to afford after chromatography (silica gel $\left.(1 \mathrm{~g}), \mathrm{CH}_{2} \mathrm{Cl}_{2}\right) 8.0 \mathrm{mg}(56 \%)$ of 9 .

SFC: $(5 R, 6 S) /(5 S, 6 R) \mathbf{- 9}, \mathrm{t}_{\mathrm{R}} 7.0 \min (48.4 \%) ;(5 S, 6 R) /(5 R, 6 S) \mathbf{- 9}, \mathrm{t}_{\mathrm{R}} 11.5 \min (51.6 \%)$; (Chirapak $\mathrm{AD}, 125$ bar, $3 \mathrm{~mL} / \mathrm{min}, 5 \% \mathrm{MeOH}$ in $\mathrm{CO}_{2}$ ).

\section{Chlorolactonization of 8 with 1-CBT in the presence of O-Methylcinchonidine.}

According to General Procedure, an NMR tube was charged with 1-CBT (12 mg, 0.078 mmol , 1.2 equiv), 1,2,4,5- $\mathrm{C}_{6} \mathrm{H}_{2} \mathrm{Cl}_{2}(11.1 \mathrm{mg}), \mathrm{CDCl}_{3}(550 \mu \mathrm{L}), 8(11.2 \mathrm{mg}, 0.066 \mathrm{mmol})$, and a solution of $O$-methylcinchonidine $\left(2.0 \mathrm{mg}\right.$ in $100 \mu \mathrm{L}$ of $\mathrm{CDCl}_{3}, 0.0065 \mathrm{mmol}, 0.1$ equiv). A yield of $81 \%$ was observed by ${ }^{1} \mathrm{H}$ NMR spectroscopy after $2.2 \mathrm{~h}$. The reaction was quenched after $3 \mathrm{~h}$ to afford after chromatography (silica gel $\left.(1 \mathrm{~g}), \mathrm{CH}_{2} \mathrm{Cl}_{2}\right) 8.0 \mathrm{mg}(56 \%)$ of 9 .

SFC: $(5 R, 6 S) /(5 S, 6 R) \mathbf{- 9}, \mathrm{t}_{\mathrm{R}} 7.0 \min (49.5 \%) ;(5 S, 6 R) /(5 R, 6 S) \mathbf{- 9}, \mathrm{t}_{\mathrm{R}} 11.5 \min (50.5 \%)$; (Chirapak $\mathrm{AD}, 125$ bar, $3 \mathrm{~mL} / \mathrm{min}, 5 \% \mathrm{MeOH}$ in $\mathrm{CO}_{2}$ ).

Chlorolactonization of 8 with $1-\mathrm{CBT}$ in the presence of $(1 R, 3 S, 5 a S, 7 a S, 7 b R)$ Octahydro-1-benzyloxy-1-phenyl-7b-methyl-2H-cyclopenta[gh]pyrrolizine.

According to General Procedure, an NMR tube was charged with 1-CBT (12 mg, 0.078 mmol , 1.2 equiv), 1,2,4,5- $\mathrm{C}_{6} \mathrm{H}_{2} \mathrm{Cl}_{2}(11.1 \mathrm{mg}), \mathrm{CDCl}_{3}(600 \mu \mathrm{L}), 8(11.2 \mathrm{mg}, 0.066 \mathrm{mmol})$, and a solution of catalyst $\left(2.1 \mathrm{mg}\right.$ in $50 \mu \mathrm{L}$ of $\mathrm{CDCl}_{3}, 0.0065 \mathrm{mmol}, 0.1$ equiv). A yield of $96 \%$ was observed by ${ }^{1} \mathrm{H}$ NMR spectroscopy after $2 \mathrm{~h}$. The reaction was quenched after $3 \mathrm{~h}$ to afford after chromatography (silica gel $\left.(1 \mathrm{~g}), \mathrm{CH}_{2} \mathrm{Cl}_{2}\right) 8.5 \mathrm{mg}(62 \%)$ of 9 . 
SFC: $(5 R, 6 S) /(5 S, 6 R) \mathbf{- 9}, \mathrm{t}_{\mathrm{R}} 7.0 \min (51.1 \%) ;(5 S, 6 R) /(5 R, 6 S) \mathbf{- 9}, \mathrm{t}_{\mathrm{R}} 11.5 \min (48.9 \%)$; (Chirapak $\mathrm{AD}, 125 \mathrm{bar}, 3 \mathrm{~mL} / \mathrm{min}, 5 \% \mathrm{MeOH}$ in $\mathrm{CO}_{2}$ ).

Chlorolactonization of 8 with 1-CBT in the presence of $(R, R)-N, N_{,}, N^{\prime}, N^{\prime}-$ Tetramethylcyclohexanediamine.

According to General Procedure, an NMR tube was charged with 1-CBT (12 mg, 0.078 mmol , 1.2 equiv), 1,2,4,5- $\mathrm{C}_{6} \mathrm{H}_{2} \mathrm{Cl}_{2}(11.1 \mathrm{mg}), \mathrm{CDCl}_{3}(600 \mu \mathrm{L}), 8(11.2 \mathrm{mg}, 0.066 \mathrm{mmol})$, and a solution of catalyst $\left(2.1 \mathrm{mg}\right.$ in $50 \mu \mathrm{L}$ of $\mathrm{CDCl}_{3}, 0.0065 \mathrm{mmol}, 0.1$ equiv). A yield of $73 \%$ was observed by ${ }^{1} \mathrm{H}$ NMR spectroscopy after $22.5 \mathrm{~h}$. The reaction was quenched after $24 \mathrm{~h}$ to afford after chromatography (silica gel $\left.(1 \mathrm{~g}), \mathrm{CH}_{2} \mathrm{Cl}_{2}\right) 8.5 \mathrm{mg}(62 \%)$ of 9 .

SFC: $(5 R, 6 S) /(5 S, 6 R) \mathbf{- 9}, \mathrm{t}_{\mathrm{R}} 7.0 \min (52.0 \%) ;(5 S, 6 R) /(5 R, 6 S) \mathbf{- 9}, \mathrm{t}_{\mathrm{R}} 11.5 \min (48.0 \%)$; (Chirapak AD, 125 bar, $3 \mathrm{~mL} / \mathrm{min}, 5 \% \mathrm{MeOH}$ in $\mathrm{CO}_{2}$ ).

\section{Chlorolactonization of 8 with 1-CBT in the presence of (-)-Sparteine.}

According to General Procedure, an NMR tube was charged with 1-CBT (12 mg, 0.078 mmol , 1.2 equiv), 1,2,4,5- $\mathrm{C}_{6} \mathrm{H}_{2} \mathrm{Cl}_{2}(11.1 \mathrm{mg}), \mathrm{CDCl}_{3}(600 \mu \mathrm{L}), 8(11.2 \mathrm{mg}, 0.066 \mathrm{mmol})$, and a solution of catalyst $\left(2.1 \mathrm{mg}\right.$ in $50 \mu \mathrm{L}$ of $\mathrm{CDCl}_{3}, 0.0065 \mathrm{mmol}, 0.1$ equiv). A yield of $47 \%$ was observed by ${ }^{1} \mathrm{H}$ NMR spectroscopy after $22.5 \mathrm{~h}$. The reaction was quenched after $24 \mathrm{~h}$.

SFC: $(5 R, 6 S) /(5 S, 6 R) \mathbf{- 9}, \mathrm{t}_{\mathrm{R}} 7.0 \min (52.0 \%) ;(5 S, 6 R) /(5 R, 6 S)-\mathbf{9}, \mathrm{t}_{\mathrm{R}} 11.5 \min (48.0 \%)$; (Chirapak $\mathrm{AD}, 125$ bar, $3 \mathrm{~mL} / \mathrm{min}, 5 \% \mathrm{MeOH}$ in $\mathrm{CO}_{2}$ ).

\section{Chlorolactonization of 8 with DCDMH in the presence of 15.}

According to General Procedure, an NMR tube was charged with DCDMH (47.3 mg, $0.24 \mathrm{mmol}, 1.2$ equiv), $\mathrm{CDCl}_{3}(1.0 \mathrm{~mL})$ and $\mathbf{8}\left(35.2 \mathrm{mg}, 0.2 \mathrm{mmol}, 1.0\right.$ equiv) and $\mathrm{C}_{3}$-symmetric quinuclidine 15 (6.8 mg, $0.02 \mathrm{mmol}, 0.1$ equiv). A yield of $29 \%$ was observed by ${ }^{1} \mathrm{H} \mathrm{NMR}$ spectroscopy after $21 \mathrm{~h}$. The reaction was quenched after $24 \mathrm{~h}$. 
SFC: $(5 R, 6 S) /(5 S, 6 R) \mathbf{- 9}, \mathrm{t}_{\mathrm{R}} 7.0 \min (50.0 \%) ;(5 S, 6 R) /(5 R, 6 S) \mathbf{- 9}, \mathrm{t}_{\mathrm{R}} 11.5 \min (50.0 \%)$; (Chirapak $\mathrm{AD}, 125 \mathrm{bar}, 3 \mathrm{~mL} / \mathrm{min}, 5 \% \mathrm{MeOH}$ in $\mathrm{CO}_{2}$ ).

\section{Chlorolactonization of 8 with DCDMH in the presence of 19.}

According to General Procedure, an NMR tube was charged with DCDMH (47.3 mg, $0.24 \mathrm{mmol}, 1.2$ equiv), $\mathrm{CDCl}_{3}(1.0 \mathrm{~mL})$ and $\mathbf{8}\left(35.2 \mathrm{mg}, 0.2 \mathrm{mmol}, 1.0\right.$ equiv) and $\mathrm{C}_{3}$-symmetric quinuclidine 19 (6.8 mg, $0.02 \mathrm{mmol}, 0.1$ equiv). A yield of $22 \%$ was observed by ${ }^{1} \mathrm{H}$ NMR spectroscopy after $21 \mathrm{~h}$. The reaction was quenched after $24 \mathrm{~h}$.

SFC: $(5 R, 6 S) /(5 S, 6 R)-\mathbf{9}, \mathrm{t}_{\mathrm{R}} 7.0 \min (50.0 \%) ;(5 S, 6 R) /(5 R, 6 S) \mathbf{- 9}, \mathrm{t}_{\mathrm{R}} 11.5 \min (50.0 \%)$; (Chirapak $\mathrm{AD}, 125$ bar, $3 \mathrm{~mL} / \mathrm{min}, 5 \% \mathrm{MeOH}$ in $\mathrm{CO}_{2}$ ).

\section{Chlorolactonization of 8 with DCDMH in the presence of 20.}

According to General Procedure, an NMR tube was charged with DCDMH (47.3 mg, $0.24 \mathrm{mmol}, 1.2$ equiv), $\mathrm{CDCl}_{3}(1.0 \mathrm{~mL})$ and $8(35.2 \mathrm{mg}, 0.2 \mathrm{mmol}, 1.0$ equiv) and diphenyl quinuclidine 20 (5.3 mg, $0.02 \mathrm{mmol}, 0.1$ equiv). A yield of $75 \%$ was observed by ${ }^{1} \mathrm{H}$ NMR spectroscopy after $1.5 \mathrm{~h}$. The reaction was quenched after $3 \mathrm{~h}$.

SFC: $(5 R, 6 S) /(5 S, 6 R) \mathbf{- 9}, \mathrm{t}_{\mathrm{R}} 7.0 \min (50.0 \%) ;(5 S, 6 R) /(5 R, 6 S) \mathbf{- 9}, \mathrm{t}_{\mathrm{R}} 11.5 \min (50.0 \%)$; (Chirapak $\mathrm{AD}, 125$ bar, $3 \mathrm{~mL} / \mathrm{min}, 5 \% \mathrm{MeOH}$ in $\mathrm{CO}_{2}$ ).

\section{Chlorolactonization of Model Substrates.}

Chlorolactonization of 22 with DCDMH in the presence of quinuclidine (Scheme 11).

An 5-mm, oven-dried NMR tube equipped with a septum was charged with DCDMH (47.3 mg, $0.24 \mathrm{mmol}, 1.2$ equiv) and then the tube was purged with Ar through a needle. Deuterochloroform (with $1 \% \mathrm{v} / \mathrm{v}$ TMS) $(1.0 \mathrm{~mL})$ was added via syringe and then the tube was agitated with a vortex mixer. $22(58.1 \mathrm{mg}, 0.2 \mathrm{mmol}, 1.0$ equiv) was added as an oil and then the 
tube was agitated with a vortex mixer. The reaction mixture was analyzed by ${ }^{1} \mathrm{H}$ NMR spectroscopy and then quinuclidine $(5.3 \mathrm{mg}, 0.02 \mathrm{mmol}, 0.1$ equiv was added and then the tube was agitated with a vortex mixer. The reaction mixture was analyzed by ${ }^{1} \mathrm{H}$ NMR spectroscopy after $12 \mathrm{~h}$. A yield of $3 \%$ was calculated by comparing the integrated area of the signal of tetramethylsilane standard $(\delta 0.0(\mathrm{~s}, 12 \mathrm{H}))$ with the signal for $\mathrm{H}-6$ of $9(\delta 5.49(\mathrm{~d}, \mathrm{~J}=5.8 \mathrm{~Hz}$, $1 \mathrm{H}))$.

Chlorolactonization of 23 with DCDMH in the absence of the catalyst (Table 2, Entry 1).

A 5-mm, oven-dried NMR tube equipped with a septum was charged with 23 (83.5 mg, 0.2 mmol, 1.0 equiv) and then the tube was purged with Ar through a needle. Deuteriochloroform (with $1 \% \mathrm{v} / \mathrm{v}$ TMS $)(1.0 \mathrm{~mL})$ was added via syringe and then the tube was agitated with a vortex mixer. The reaction mixture was analyzed by ${ }^{1} \mathrm{H}$ NMR spectroscopy and then DCDMH (47.3 mg, $0.24 \mathrm{mmol}, 1.2$ equiv) was added and then the tube was agitated with a vortex mixer. The reaction mixture was analyzed by ${ }^{1} \mathrm{H}$ NMR spectroscopy after $2.5 \mathrm{~h}$. Yields of $46 \%$ for 9 and $17 \%$ for 24 were calculated by comparing the integrated area of the signal of tetramethylsilane standard $(\delta 0.0(\mathrm{~s}, 12 \mathrm{H}))$ with the signal for $\mathrm{H}-6$ of $9(\delta 5.49(\mathrm{~d}, \mathrm{~J}=5.8 \mathrm{~Hz}$, $1 \mathrm{H}))$ and $\mathrm{H}-6$ of $9(\delta 5.07(\mathrm{~d}, \mathrm{~J}=5.5 \mathrm{~Hz}, 1 \mathrm{H}))$ correspondingly.

\section{Chlorolactonization of 23 with DCDMH in the presence of 20 (Table 2, Entry 2).}

A 5-mm, oven-dried NMR tube equipped with a septum was charged with 23 (83.5 mg, $0.2 \mathrm{mmol}, 1.0$ equiv) and diphenyl quinuclidine 20 (5.3 $\mathrm{mg}, 0.02 \mathrm{mmol}, 0.1$ equiv), then the tube was purged with Ar through a needle. Deuteriochloroform (with 1\% v/v TMS) (1.0 mL) was added via syringe and then the tube was agitated with a vortex mixer. The reaction mixture was analyzed by ${ }^{1} \mathrm{H}$ NMR spectroscopy and then DCDMH (47.3 mg, $0.24 \mathrm{mmol}, 1.2$ equiv) was 
added and the tube was agitated with a vortex mixer. The reaction mixture was analyzed by ${ }^{1} \mathrm{H}$ NMR spectroscopy after 2.5 h. Yields of $48 \%$ for 9 and $16 \%$ for 24 were calculated by comparing the integrated area of the signal of tetramethylsilane standard $(\delta 0.0(\mathrm{~s}, 12 \mathrm{H}))$ with the signal for H-6 of $9(\delta 5.49(\mathrm{~d}, \mathrm{~J}=5.8 \mathrm{~Hz}, 1 \mathrm{H}))$ and $\mathrm{H}-6$ of $9(\delta 5.07(\mathrm{~d}, \mathrm{~J}=5.5 \mathrm{~Hz}, 1 \mathrm{H}))$ correspondingly.

\section{Chlorolactonization of 23 with DCDMH in the presence of quinuclidine (Table 2,}

\section{Entry 3).}

A 5-mm, oven-dried NMR tube equipped with a septum was charged with 23 (83.5 mg, $0.2 \mathrm{mmol}, 1.0$ equiv) and quinuclidine ( $2.2 \mathrm{mg}, 0.02 \mathrm{mmol}, 0.1$ equiv), then the tube was purged with Ar through a needle. Deuteriochloroform (with $1 \% \mathrm{v} / \mathrm{v}$ TMS) $(1.0 \mathrm{~mL})$ was added via syringe and then the tube was agitated with a vortex mixer. The reaction mixture was analyzed by ${ }^{1} \mathrm{H}$ NMR spectroscopy and then DCDMH (47.3 mg, $0.24 \mathrm{mmol}, 1.2$ equiv) was added and the tube was agitated with a vortex mixer. The reaction mixture was analyzed by ${ }^{1} \mathrm{H}$ NMR spectroscopy after $20 \mathrm{~min}$. Yields of $76 \%$ for $\mathbf{9}$ and $19 \%$ for $\mathbf{2 4}$ were calculated by comparing the integrated area of the signal of tetramethylsilane standard $(\delta 0.0(\mathrm{~s}, 12 \mathrm{H}))$ with the signal for H-6 of $9(\delta 5.49(\mathrm{~d}, \mathrm{~J}=5.8 \mathrm{~Hz}, 1 \mathrm{H}))$ and H-6 of $9(\delta 5.07(\mathrm{~d}, \mathrm{~J}=5.5 \mathrm{~Hz}, 1 \mathrm{H}))$ correspondingly.

\section{General Procedure. Solvolytic Substitution with 25 (Table 3).}

A 5-mm, oven-dried NMR tube equipped with a septum was charged with tetrabutylammonium acetate $(1.0-20.0$ equiv), then the tube was purged with Ar through a needle. HFIP $(0.25 \mathrm{~mL})$ and deuteriodichloromethane $(0.25 \mathrm{~mL})$ were added via syringe and then the tube was agitated with a vortex mixer. The reaction mixture was analyzed by ${ }^{1} \mathrm{H}$ NMR spectroscopy and then $25(11.7 \mathrm{mg}, 0.05 \mathrm{mmol}, 1.0$ equiv) was added via syringe and the tube was agitated with a vortex mixer. The reaction mixture was analyzed by ${ }^{1} \mathrm{H}$ NMR spectroscopy; 
conversion of starting material 25 was monitored by the disappearance of diagnostic benzylic proton signal of $\mathbf{2 5} \delta 5.69(\mathrm{~d}, J=5.45 \mathrm{~Hz}, 1 \mathrm{H})$. Diastereomeric ratio of products anti-26/syn-26 was calculated by comparing the integrated areas of benzylic signals: $\delta 5.91(\mathrm{~d}, J=5.3 \mathrm{~Hz}, 1 \mathrm{H})$ for anti-26 and $\delta 5.84(\mathrm{~d}, \mathrm{~J}=7.2 \mathrm{~Hz}, \mathbf{1 H})$ for syn-26 correspondingly.

Table 3, Entry 1.

According to General Procedure, an NMR tube was charged with tetrabutylammonium acetate $(13 \mathrm{mg}, 0.05 \mathrm{mmol}, 1.0$ equiv), HFIP $(0.25 \mathrm{~mL})$, deuteriodichloromethane $(0.25 \mathrm{~mL})$ and 25 (11.7 mg, $0.05 \mathrm{mmol}, 1.0$ equiv). The reaction mixture was analyzed by ${ }^{1} \mathrm{H}$ NMR spectroscopy; full conversion was achieved after 15 minutes. Diastereomeric ratio of products anti-26/syn-26 was determined to be 62:38 and was constant during the course of the reaction.

\section{Table 3, Entry 2.}

According to General Procedure, an NMR tube was charged with tetrabutylammonium acetate $(26.0 \mathrm{mg}, 0.1 \mathrm{mmol}, 2.0$ equiv), HFIP $(0.25 \mathrm{~mL})$, deuteriodichloromethane $(0.25 \mathrm{~mL})$ and 25 (11.7 mg, $0.05 \mathrm{mmol}, 1.0$ equiv). The reaction mixture was analyzed by ${ }^{1} \mathrm{H}$ NMR spectroscopy; full conversion was achieved after 17 minutes. Diastereomeric ratio of products anti-26/syn-26 was determined to be 60:40 and was constant during the course of the reaction.

\section{Table 3, Entry 3.}

According to General Procedure, an NMR tube was charged with tetrabutylammonium acetate $(64.9 \mathrm{mg}, 0.25 \mathrm{mmol}, 5.0$ equiv), HFIP $(0.25 \mathrm{~mL})$, deuteriodichloromethane $(0.25 \mathrm{~mL})$ and 25 (11.7 $\mathrm{mg}, 0.05 \mathrm{mmol}, 1.0$ equiv). The reaction mixture was analyzed by ${ }^{1} \mathrm{H}$ NMR spectroscopy; full conversion was achieved after 70 minutes. Diastereomeric ratio of products anti-26/syn-26 was determined to be $62: 38$ and was constant during the course of the reaction. 


\section{Table 3, Entry 4.}

According to General Procedure, an NMR tube was charged with tetrabutylammonium acetate (129.7 mg, $0.5 \mathrm{mmol}, 10.0$ equiv), HFIP (0.25 mL), deuteriodichloromethane (0.25 mL) and 25 (11.7 $\mathrm{mg}, 0.05 \mathrm{mmol}, 1.0$ equiv). The reaction mixture was analyzed by ${ }^{1} \mathrm{H}$ NMR spectroscopy; $76 \%$ conversion was achieved after $48 \mathrm{~h}$. Diastereomeric ratio of products anti26/syn-26 was determined to be 62:38 and was constant during the course of the reaction.

\section{Table 3, Entry 5.}

According to General Procedure, an NMR tube was charged with tetrabutylammonium acetate (259.5 mg, $1.0 \mathrm{mmol}, 20.0$ equiv), HFIP (0.25 mL), deuteriodichloromethane $(0.25 \mathrm{~mL})$ and 25 (11.7 mg, $0.05 \mathrm{mmol}, 1.0$ equiv). The reaction mixture was analyzed by ${ }^{1} \mathrm{H}$ NMR spectroscopy; no conversion was achieved after $48 \mathrm{~h}$.

\section{References}

(1) Wang, M.; Gao, L. X.; Mai, W. P.; Xia, A. X.; Wang, F.; Zhang, S. B. J. Org. Chem. 2004, 69, 2874.

(2) Zheng, T.; Narayan, R. S.; Schomaker, J. M.; Borhan, B. J. Am. Chem. Soc. 2005, 127, 6946.

(3) Krief, A.; Trabelsi, M.; Dumont, W.; Derock, M. Synlett 2004, 10, 1751.

(4) Janssen, R. A. J.; Kingma, J. A. J. M.; Buck, H. M. J. Am. Chem. Soc. 1988, 110, 3018.

(5) Schmutzler, R. Inorg. Chem. 1964, 3, 421.

(6) Haynes, R. K.; Indorato, C. Aust. J. Chem. 1984, 37, 1183.

(7) Sova, M.; Mravljak, J.; Kovač, A.; Pečar, S.; Časar, Z.; Gobec, S. Synthesis 2010, 2010, 3433.

(8) Hughes, T. V.; Hammond, S. D.; Cava, M. P J. Org. Chem. 1998, 63, 401. 
Denmark, Ryabchuk, Burk and Gilkert

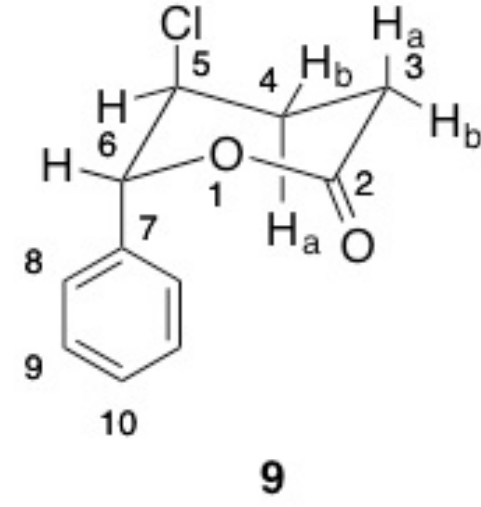

$\mathrm{HC}(9+10) \quad \mathrm{HC}(8)$

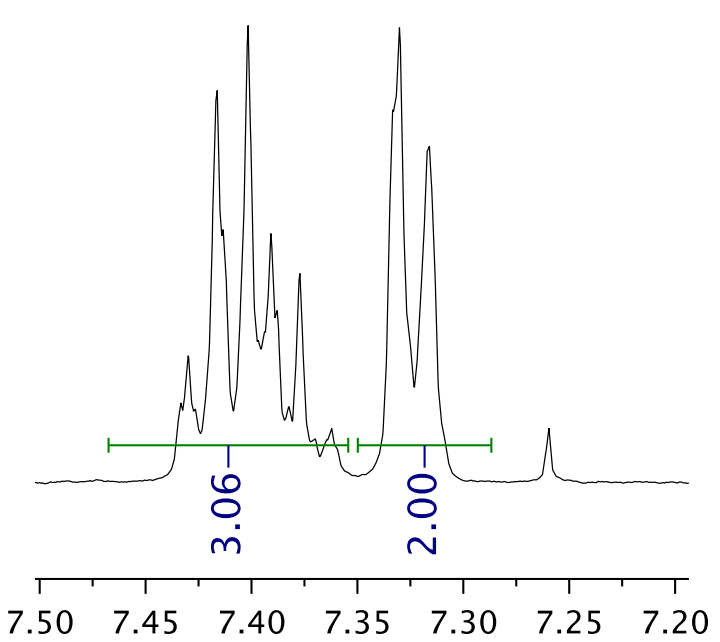

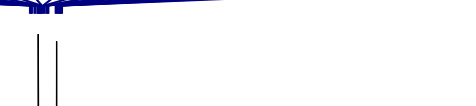

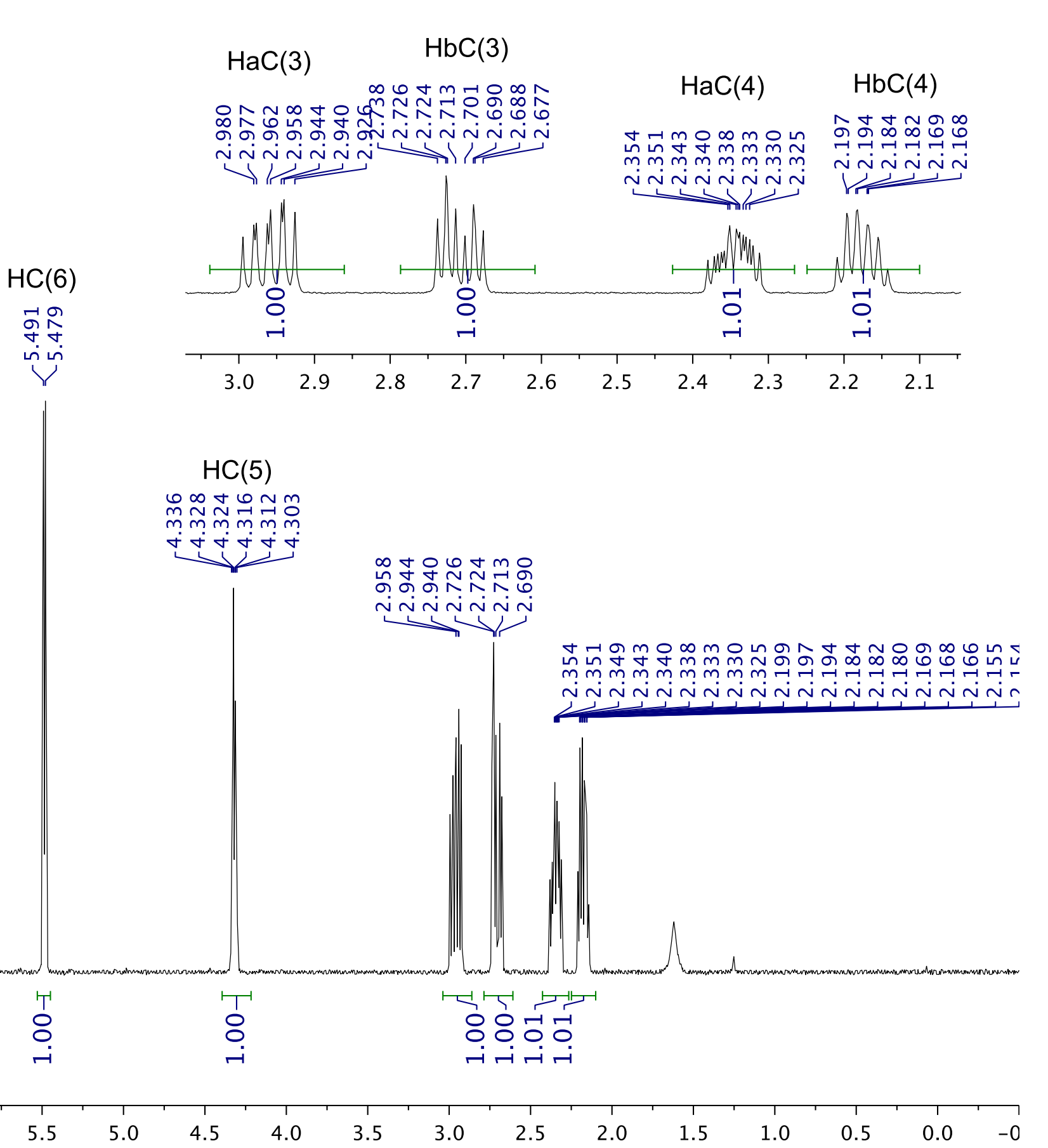





$(4)$

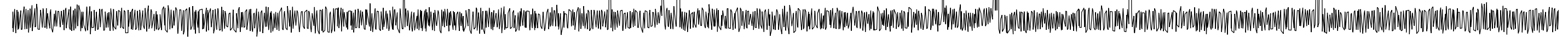









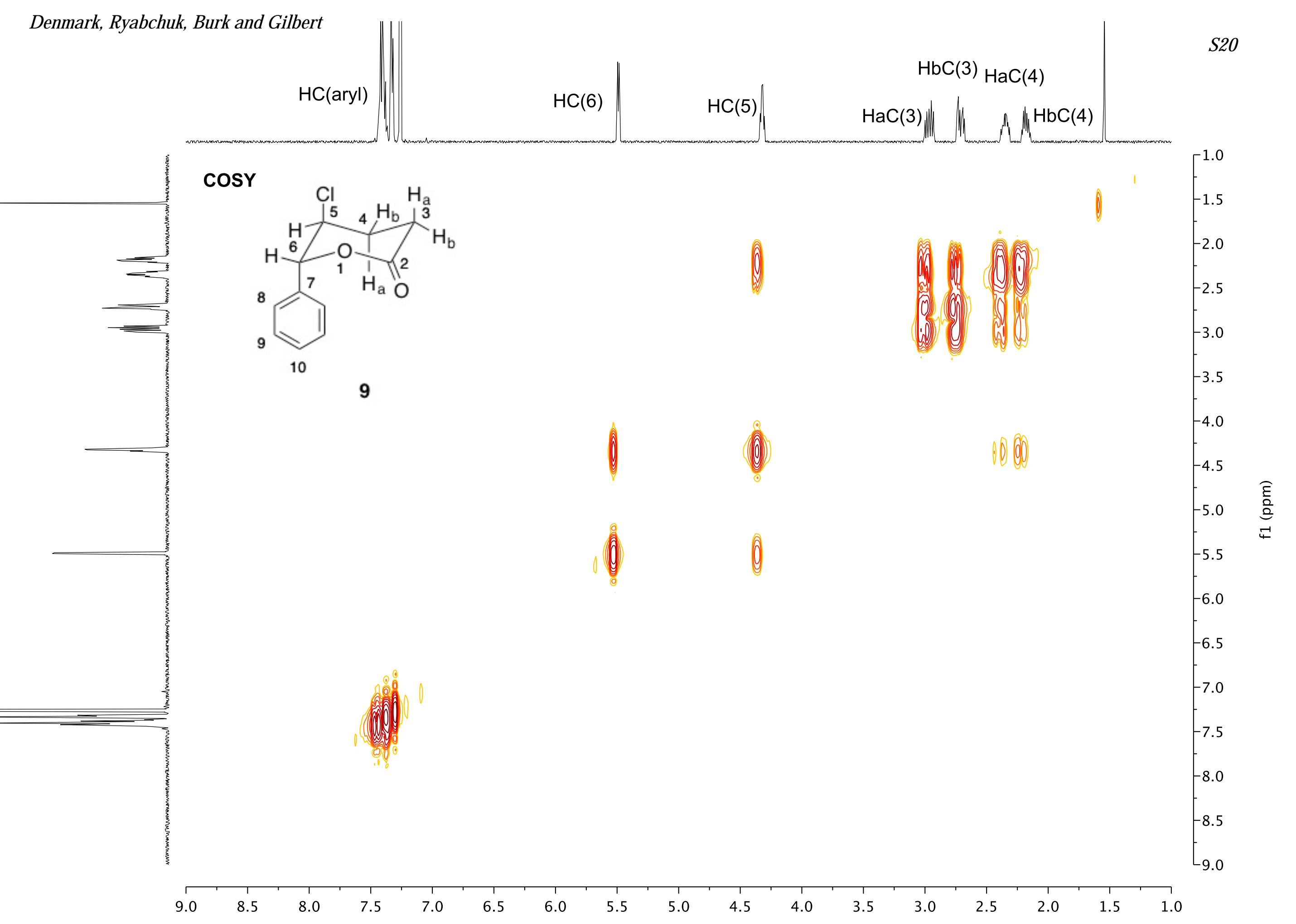




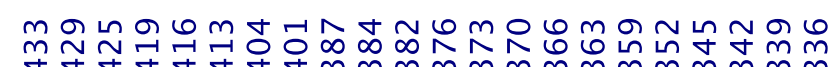

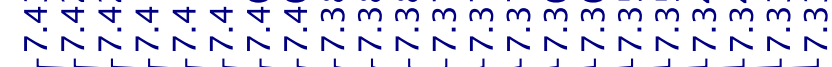



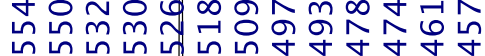
NNN M/1
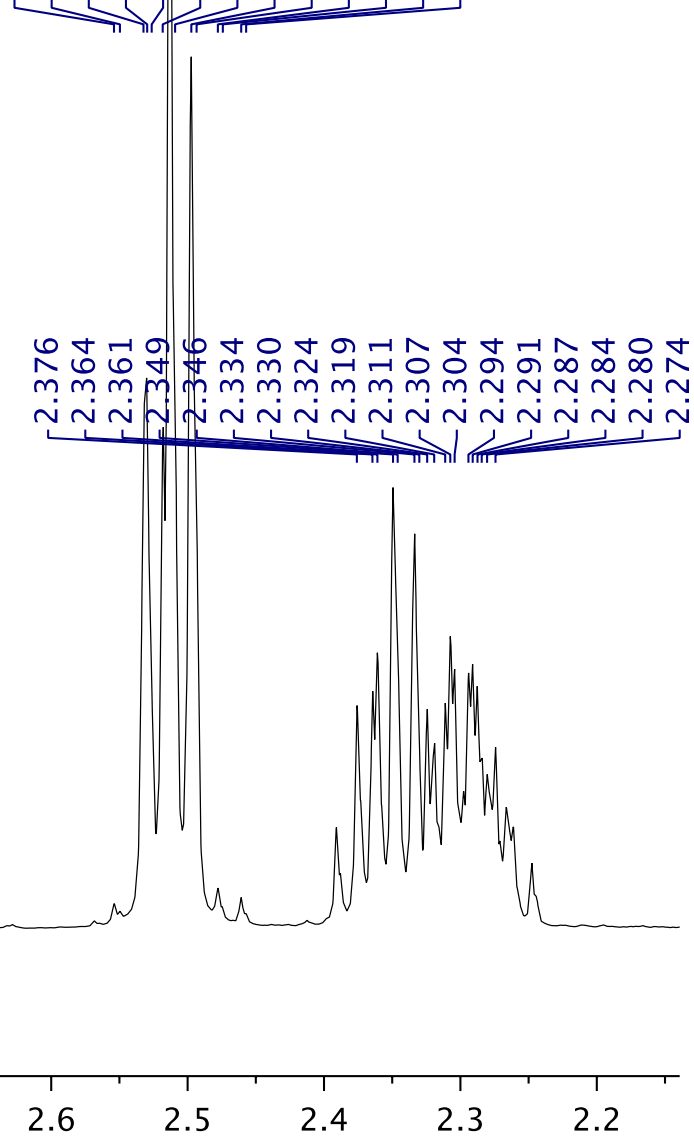

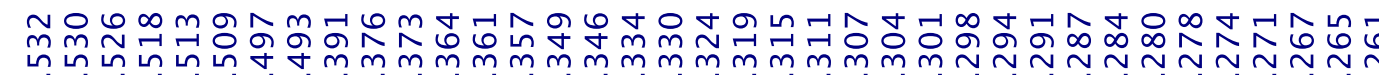

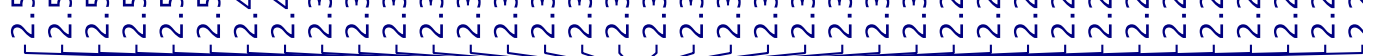

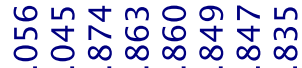
ம்
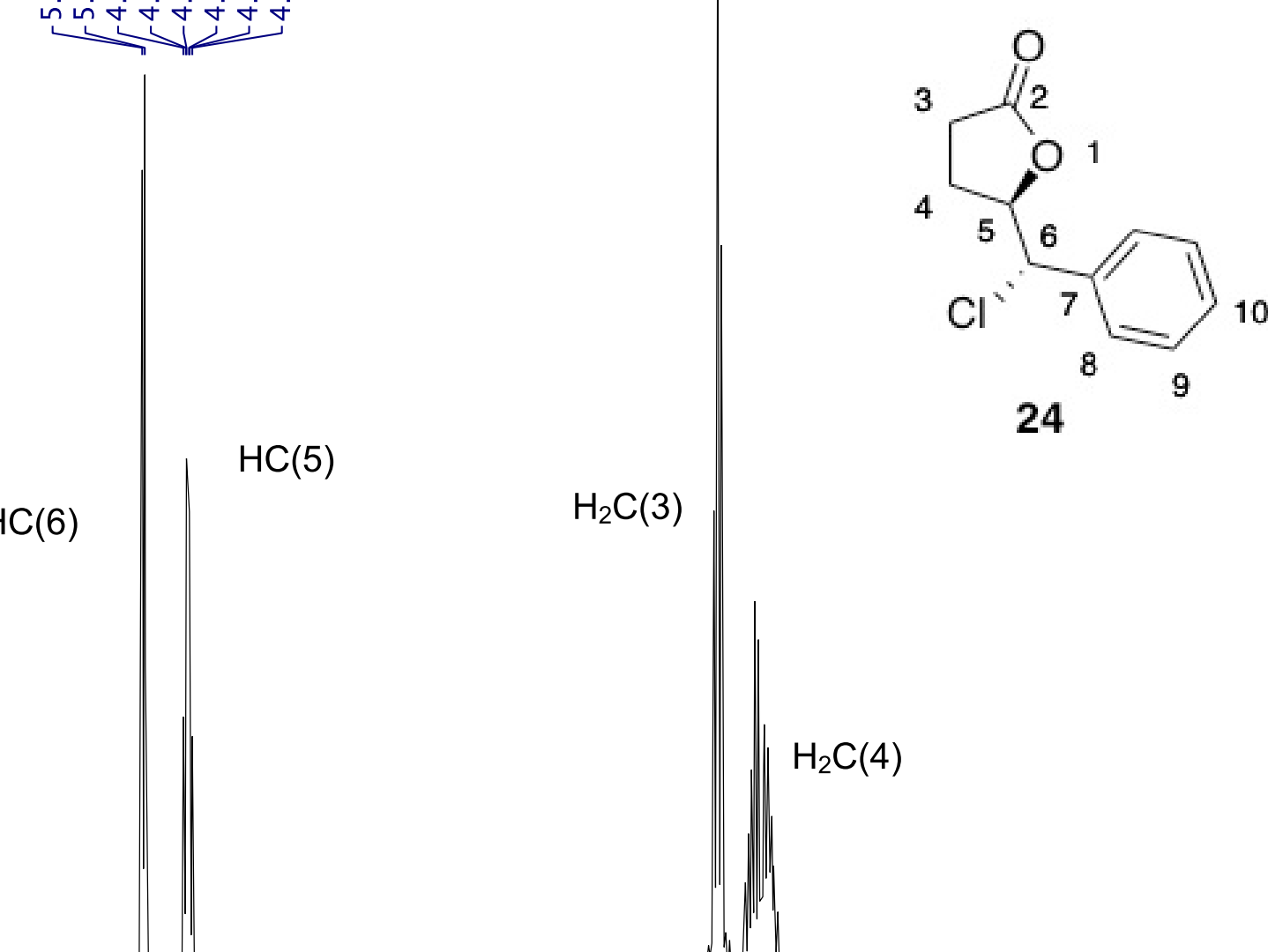

寄客 (1) 寞

ช 












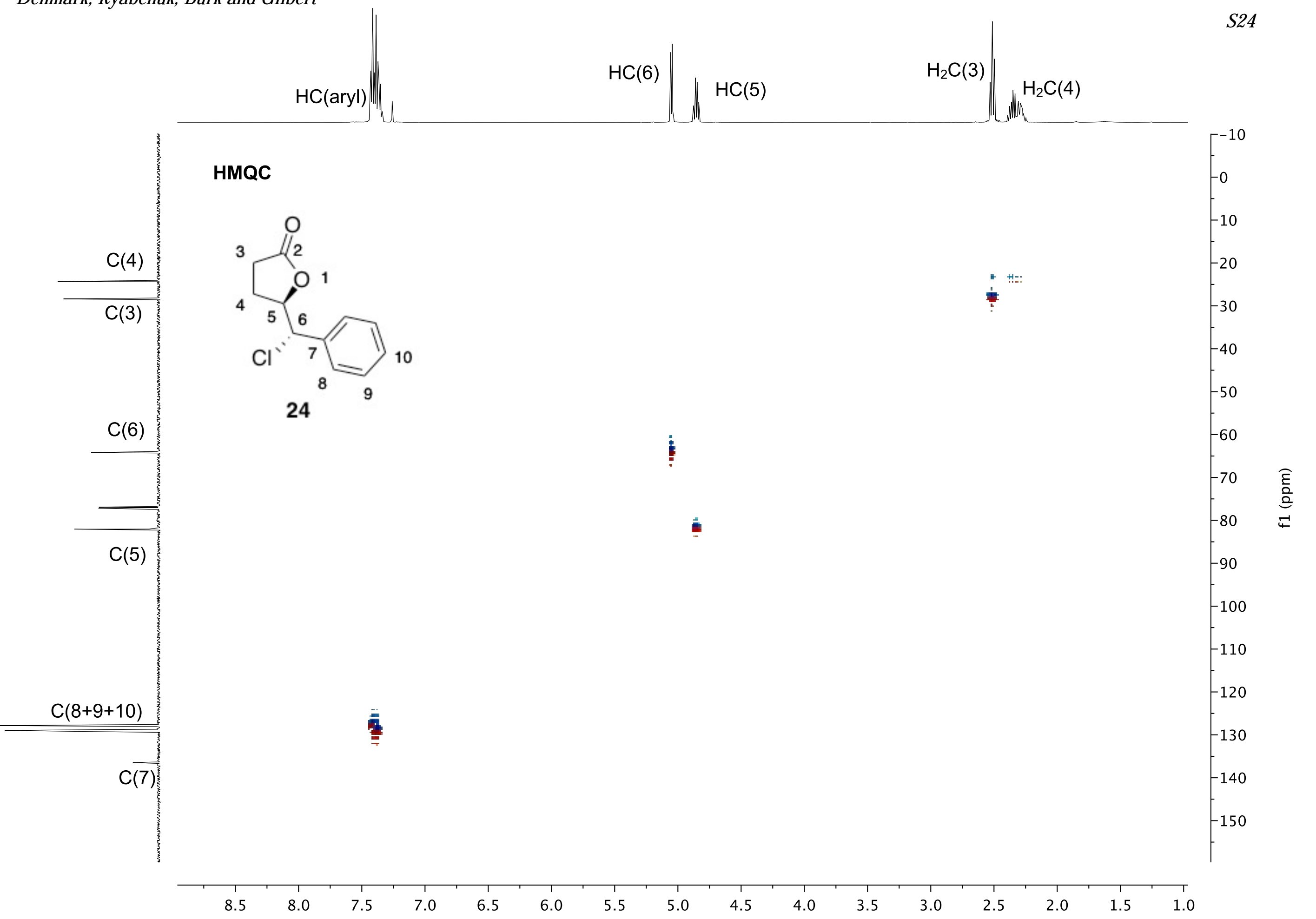




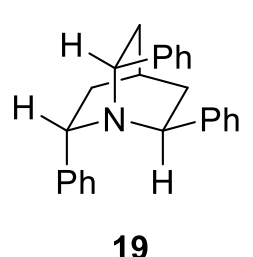

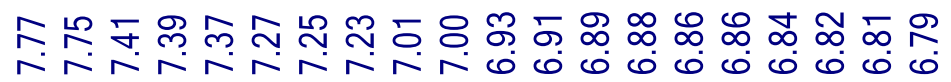

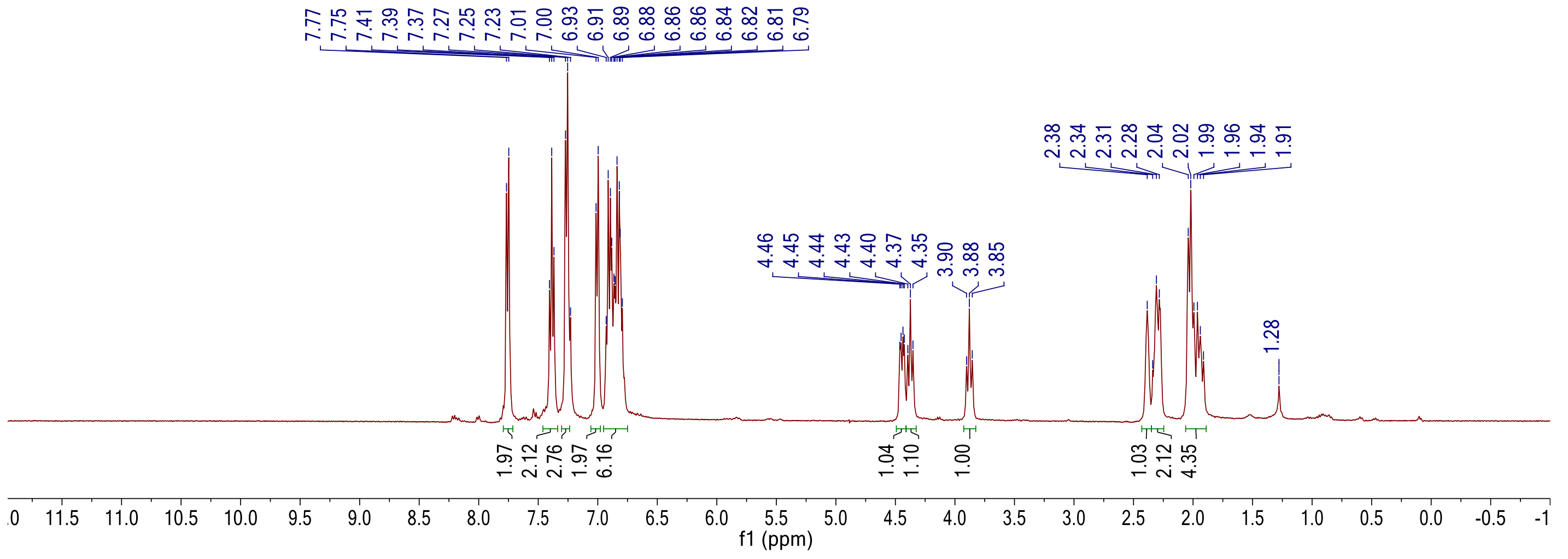


$\mathrm{Ph}_{\mathrm{H}}^{\mathrm{H}} \overbrace{\mathrm{Ph}}$

19

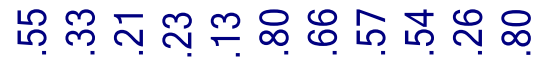

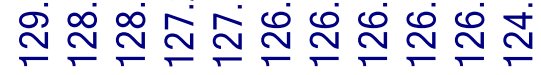

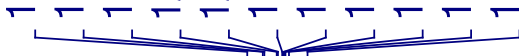

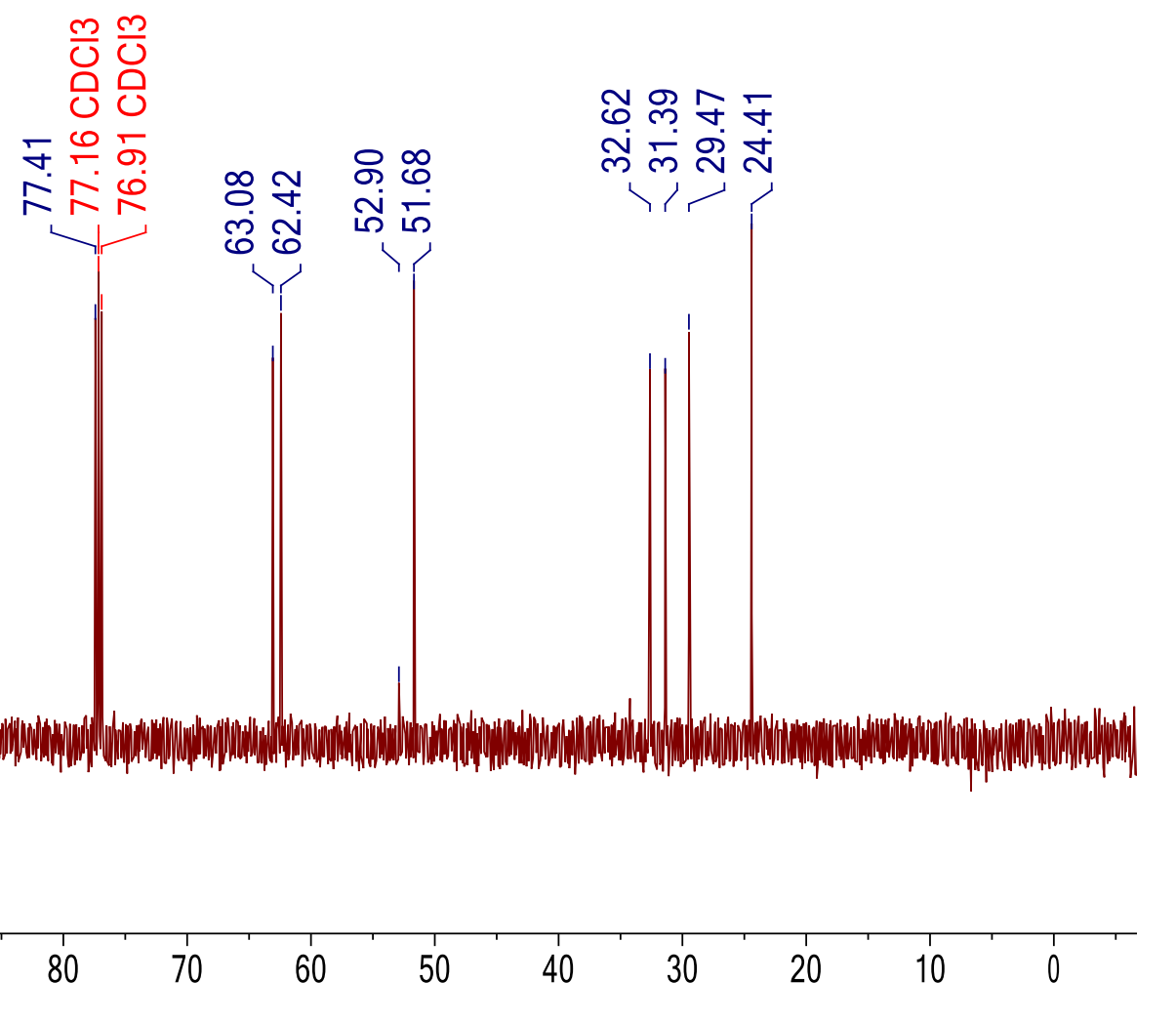




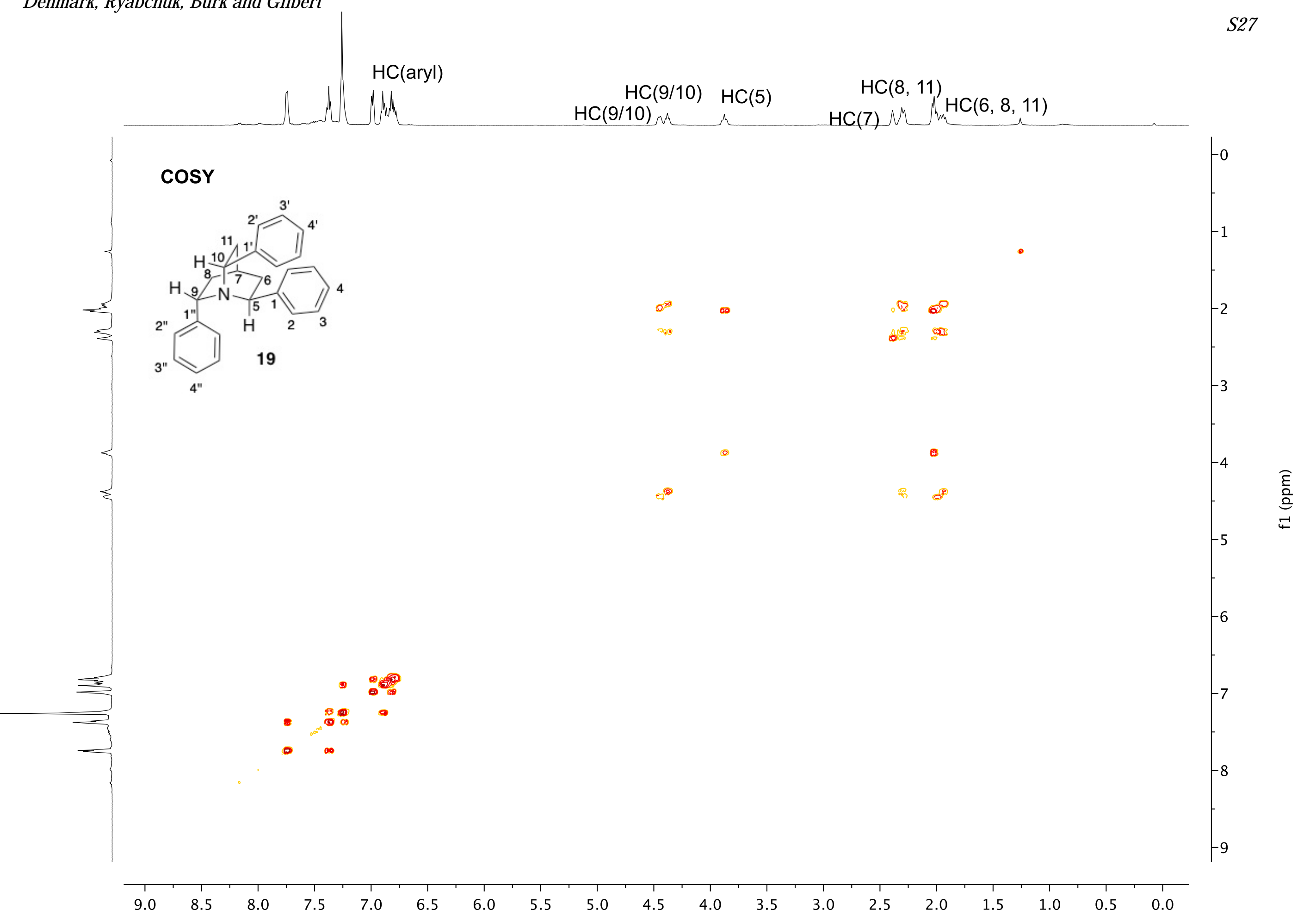




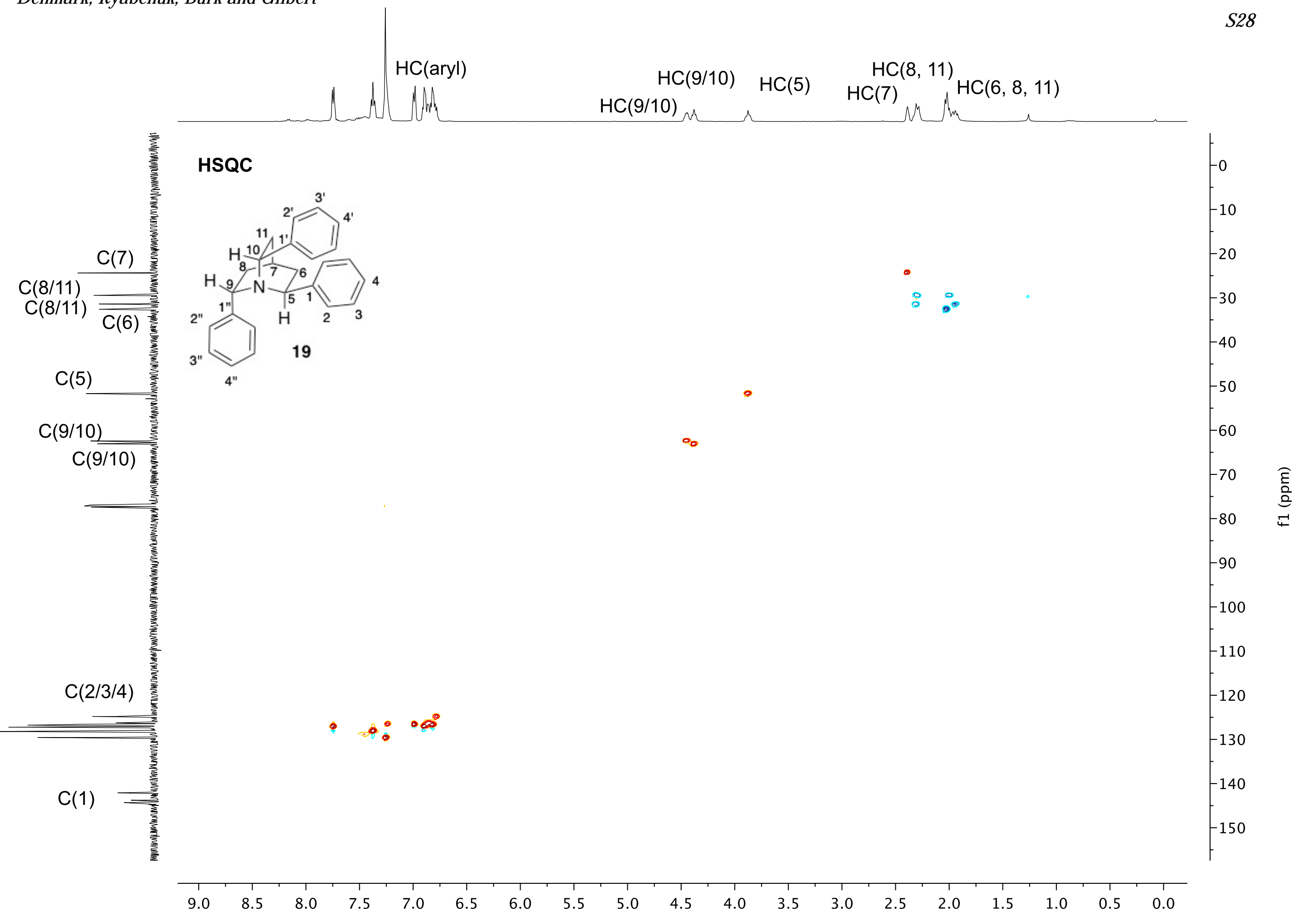


Denmark, Ryabchuk, Burk and Gilbert

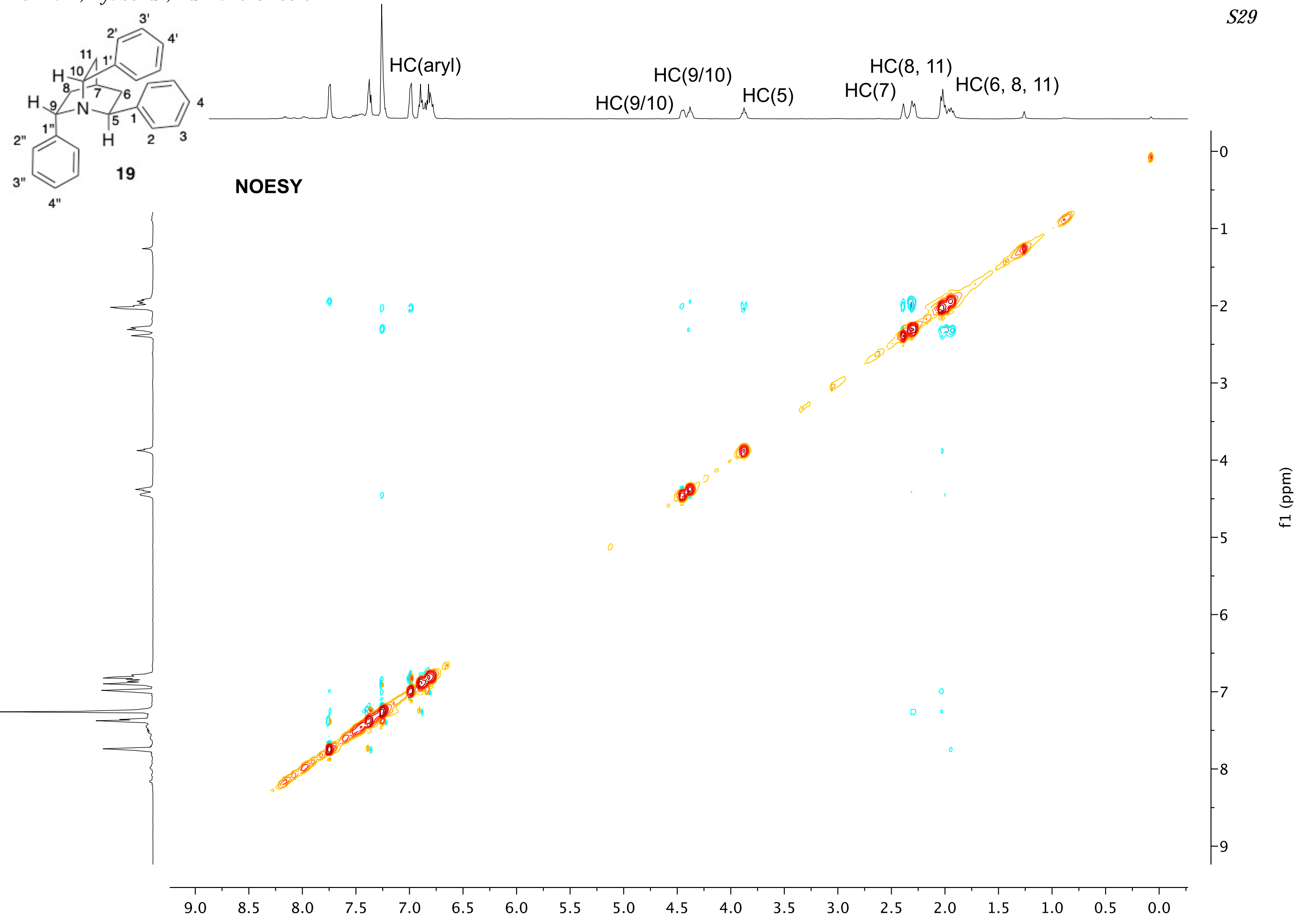




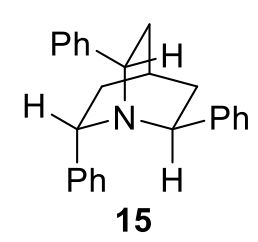

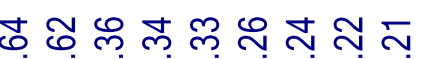

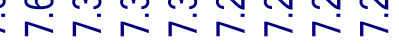






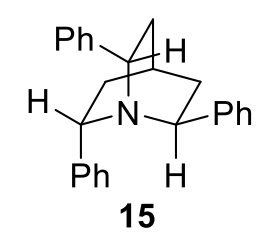

$$
\text { 幽 }
$$

$\stackrel{\infty}{\sim} \stackrel{\sim}{\sim}$

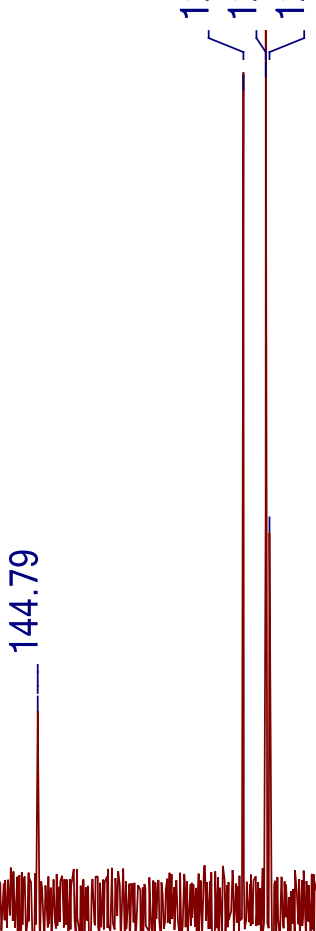

$$
\begin{aligned}
& \frac{m}{0} \frac{m}{0} \\
& 000 \\
& \text { 둥두 } \\
& \text { 숑 }
\end{aligned}
$$

๙্.

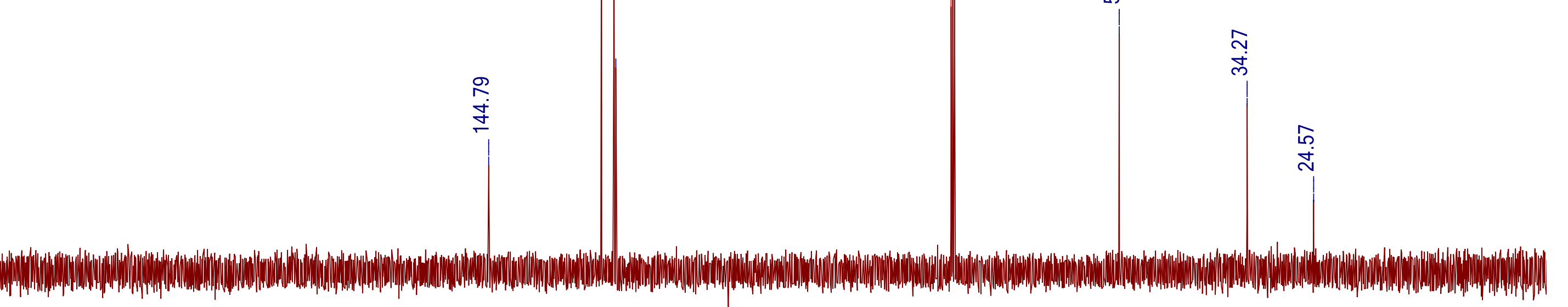




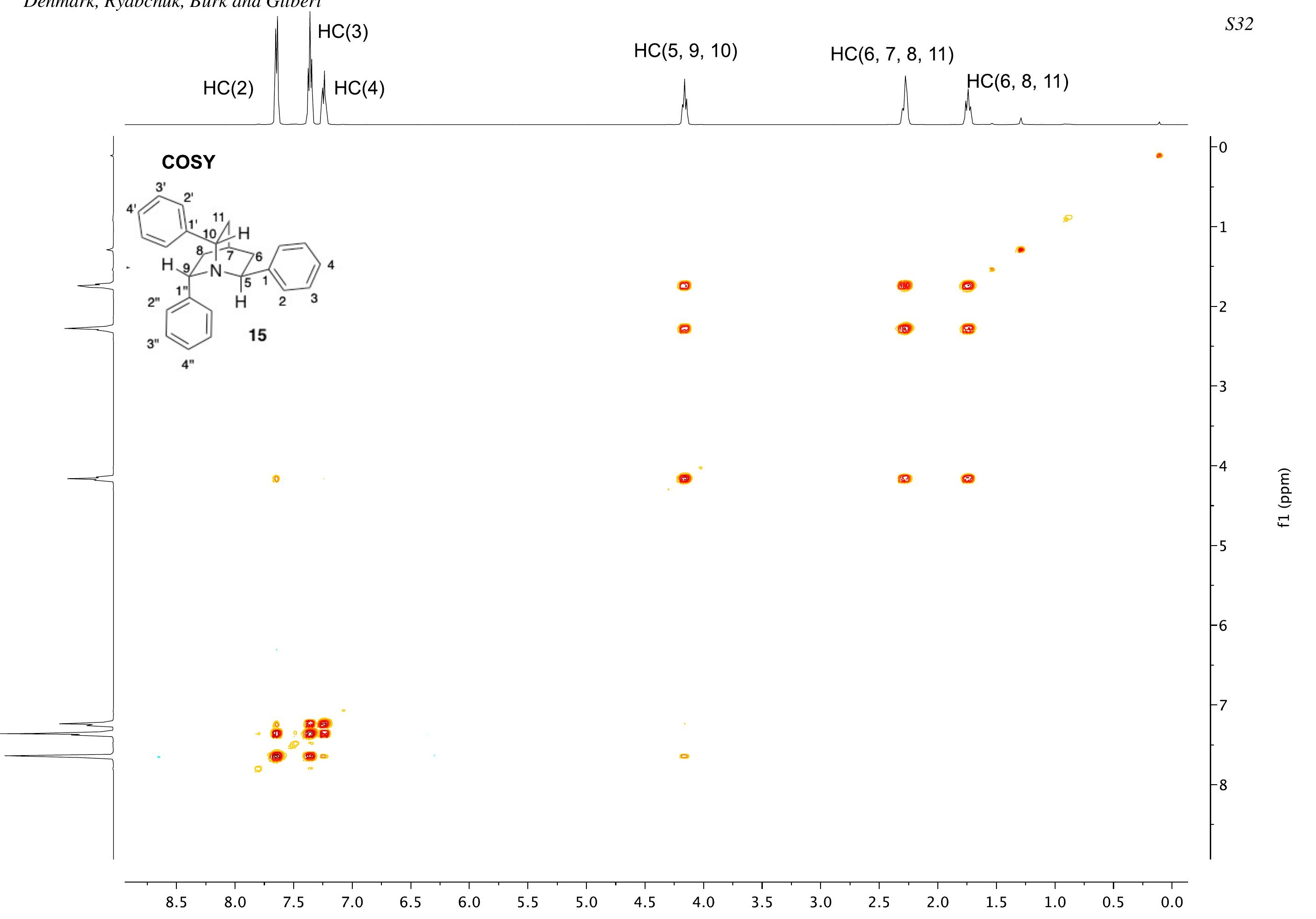




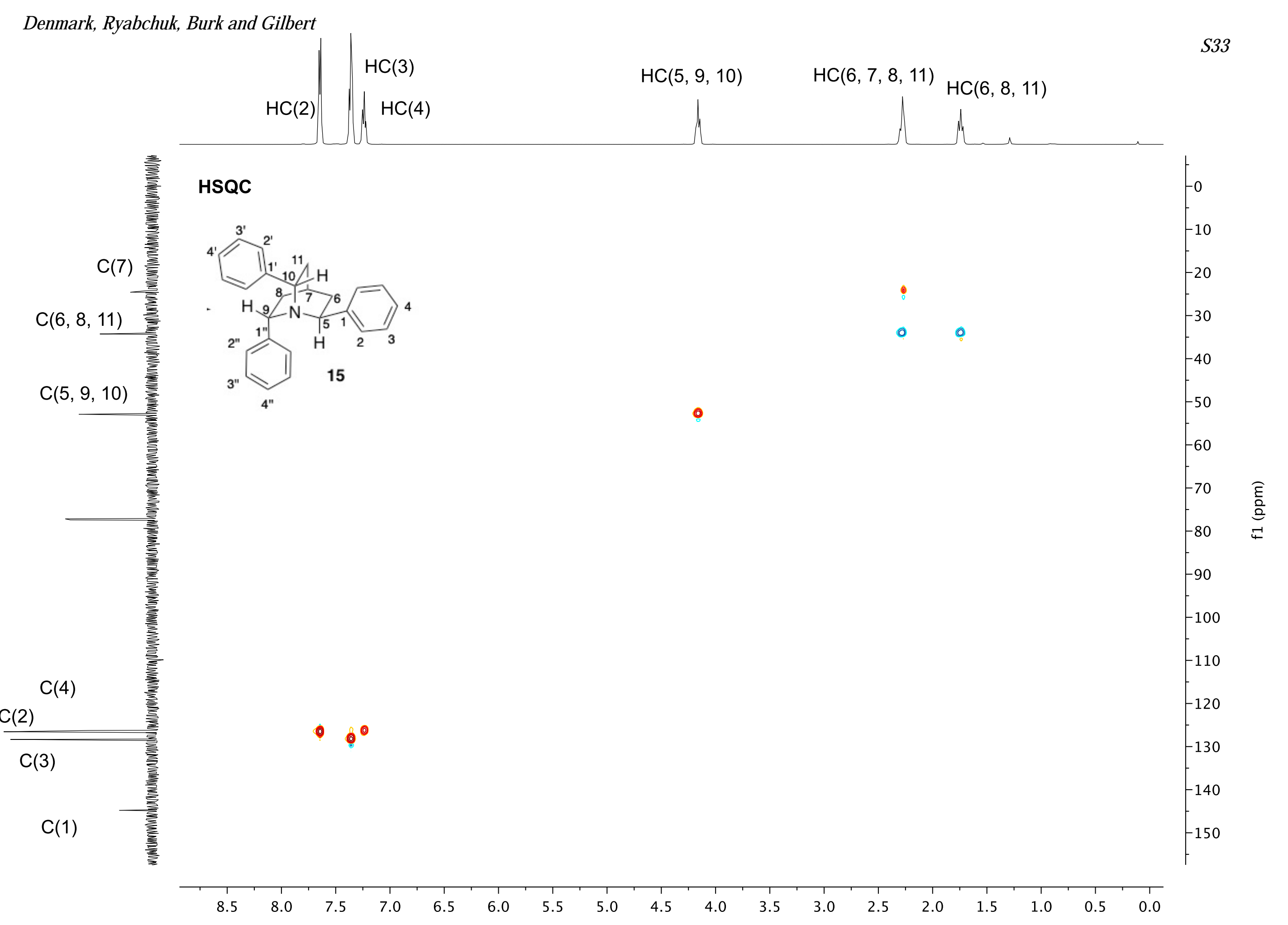



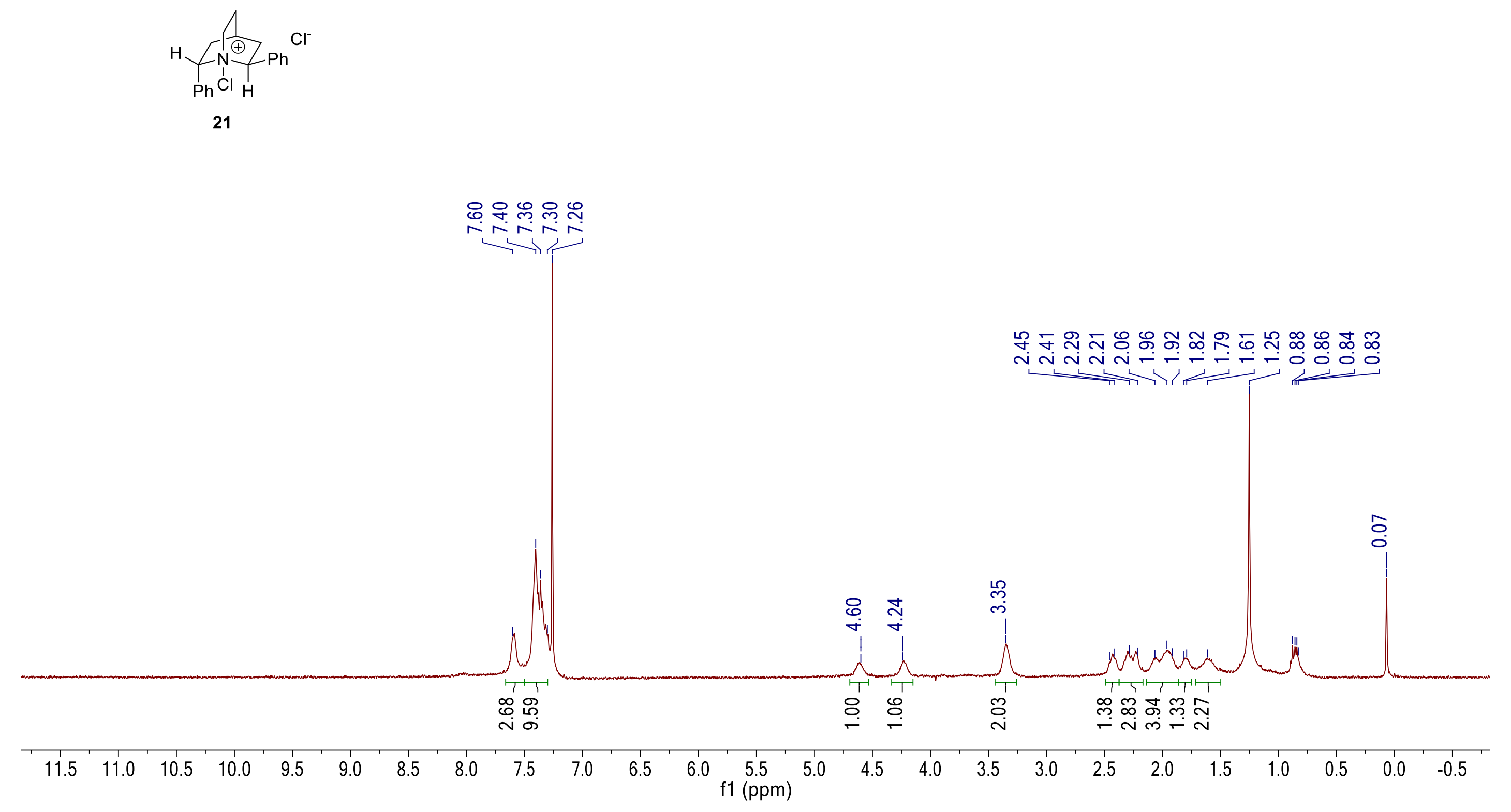


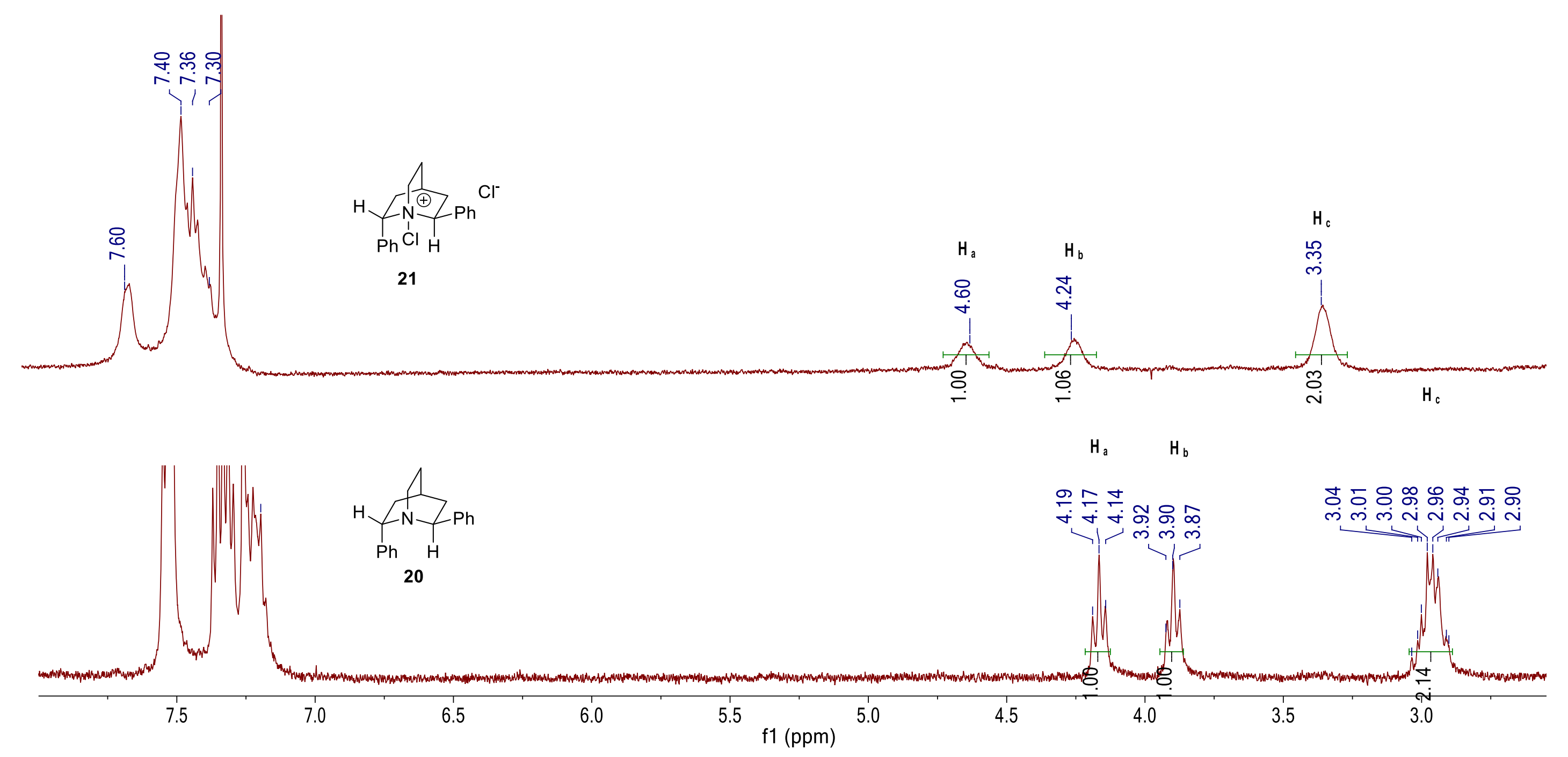




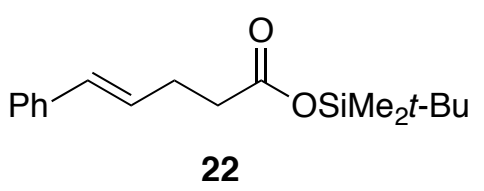

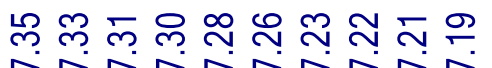

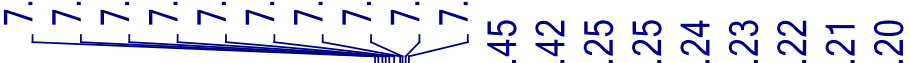

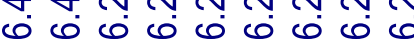

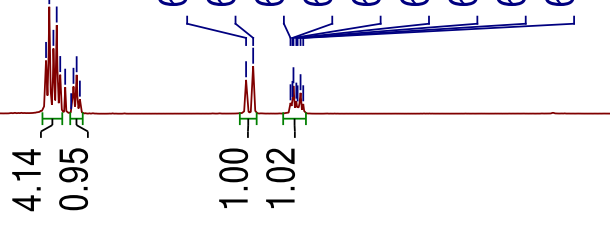

$\begin{array}{lll}11.5 & 11.0 & 10.5\end{array}$

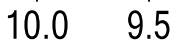

$\begin{array}{ll}.5 & 9.0\end{array}$

$8.5 \quad 8.0 \quad 7.5$

$\begin{array}{ll}7.0 & 6.5\end{array}$

$6.0 \quad 5.5$

$5.0 \quad 4.5$

1 (ppm) 


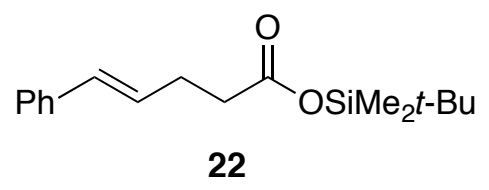

\section{도용요}

ผ่ंฝึ่ ฝ่

กํำ윰ำ

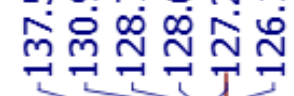

๙্

푸음

N走果

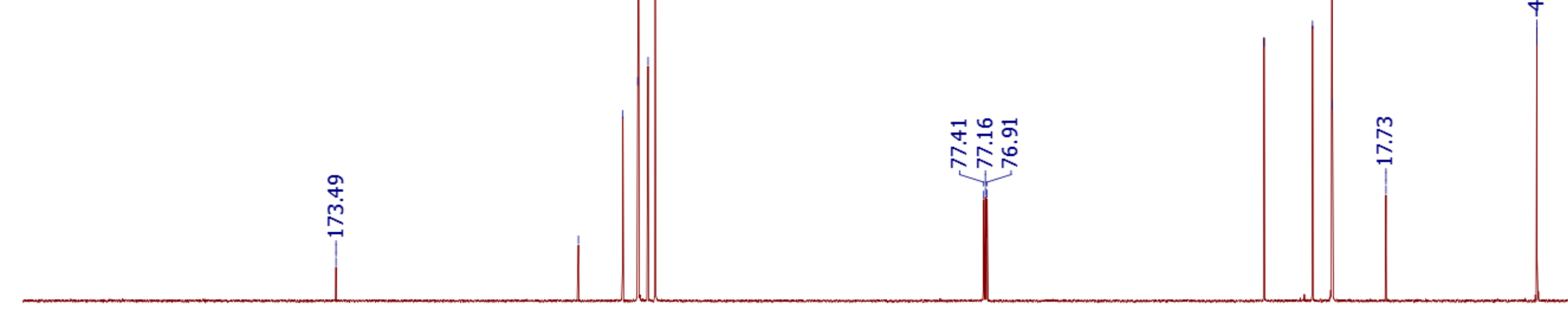



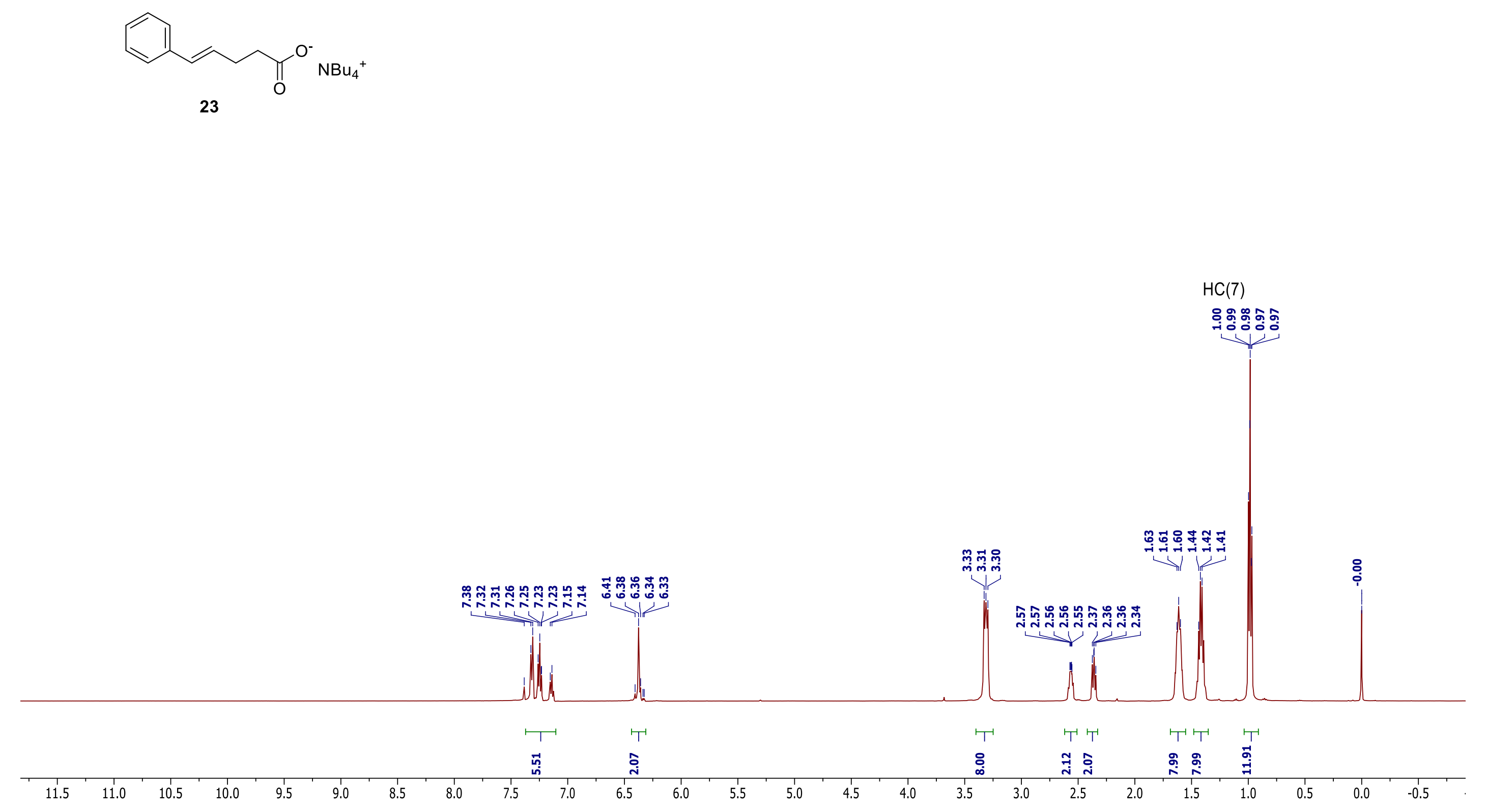


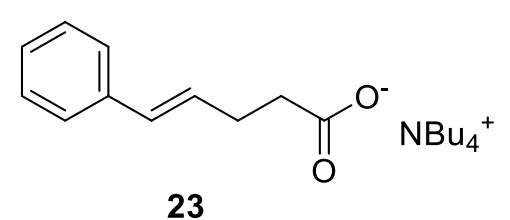

む! 능

23

लें

fำ ํํำ

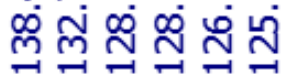

$\rightarrow$

$\infty$

N 


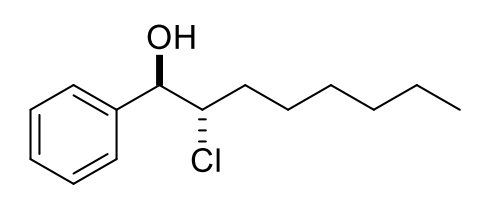

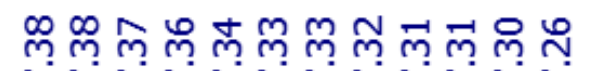
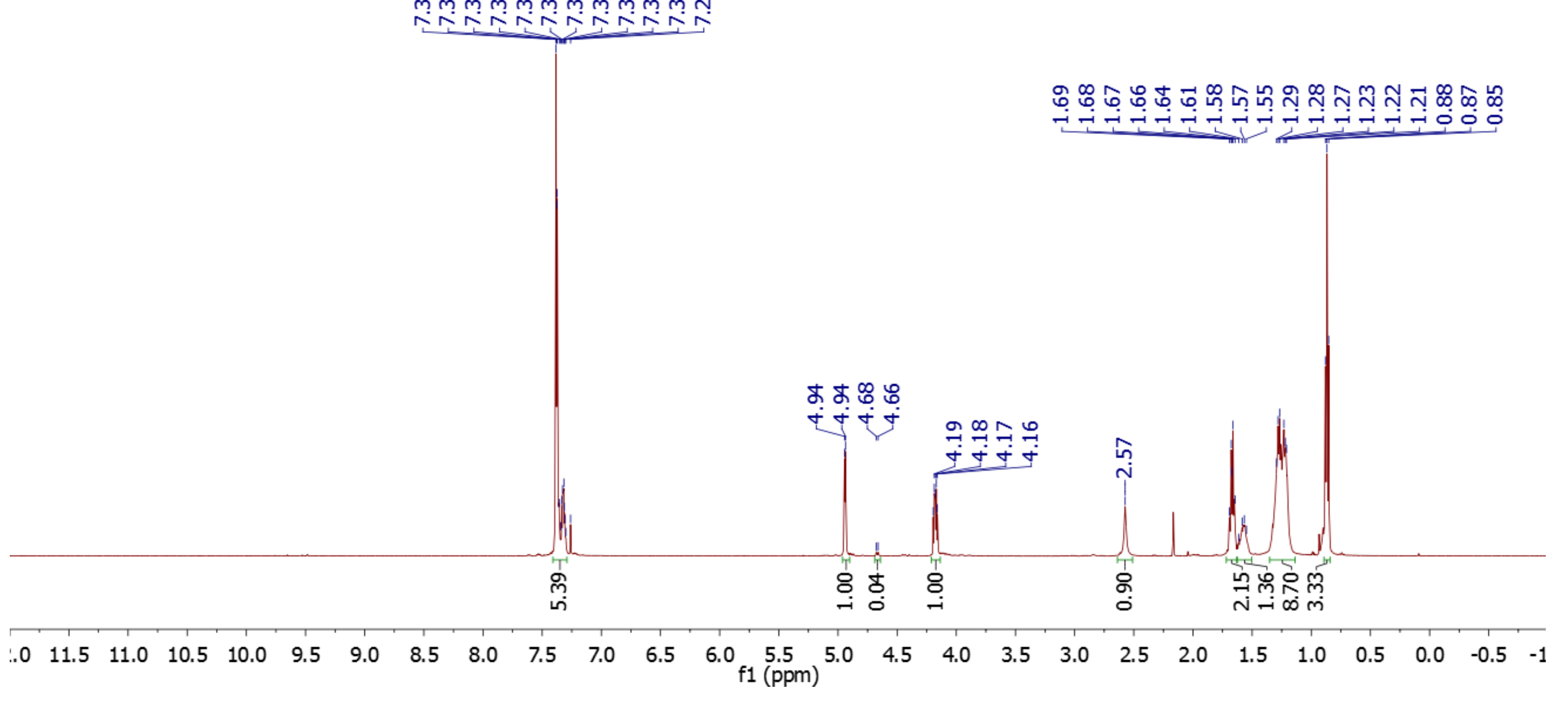


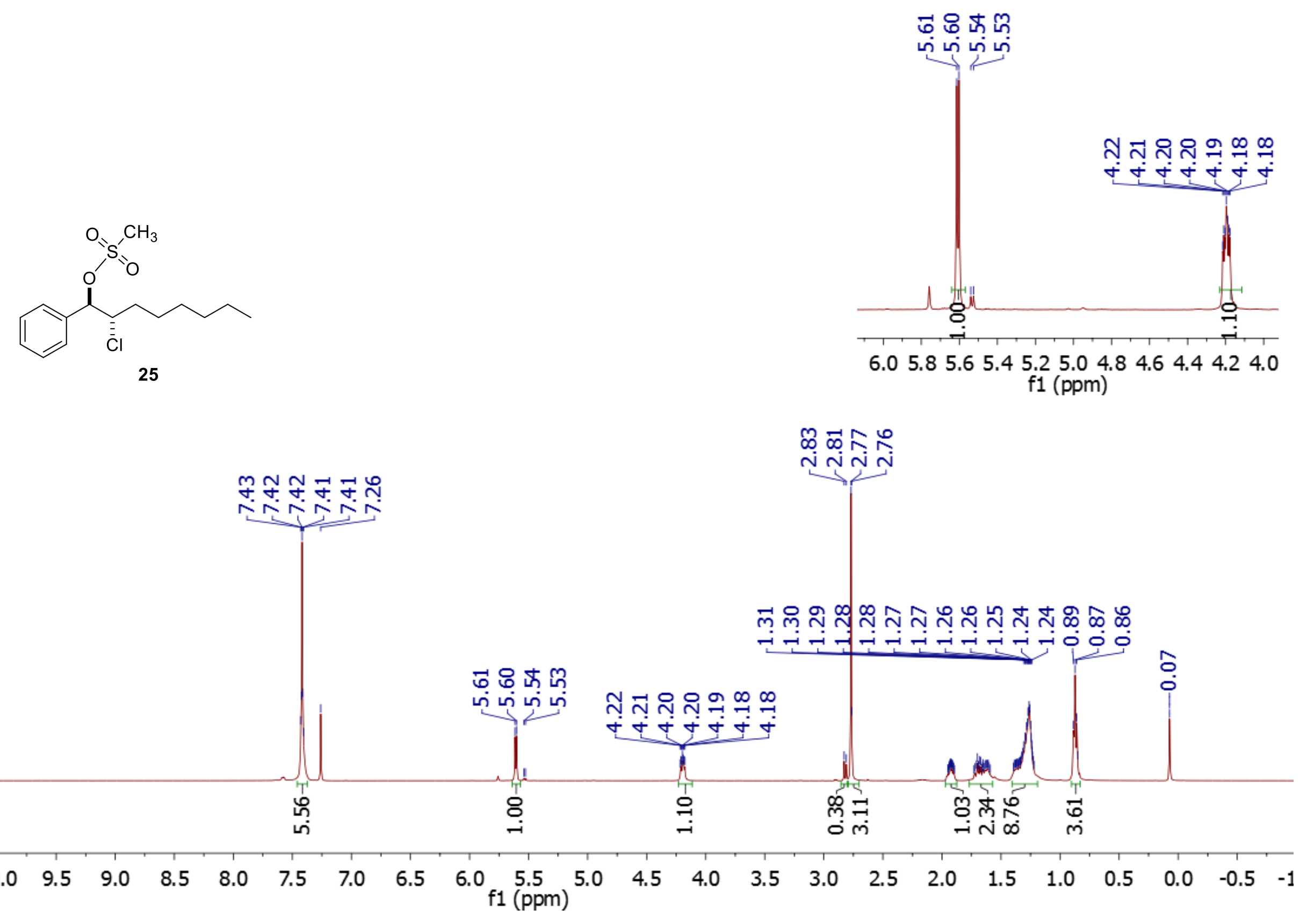




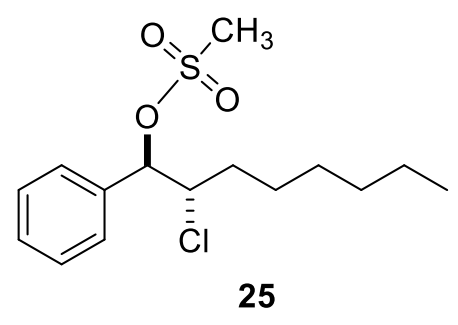

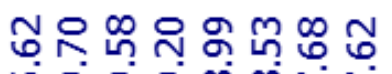

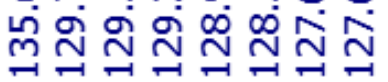

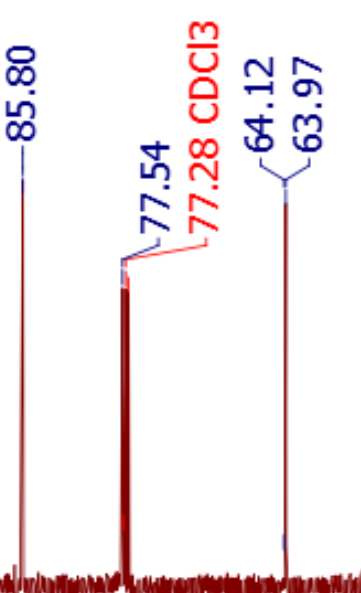

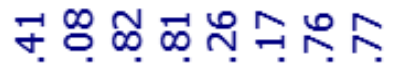

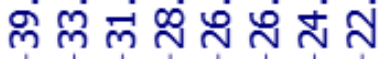

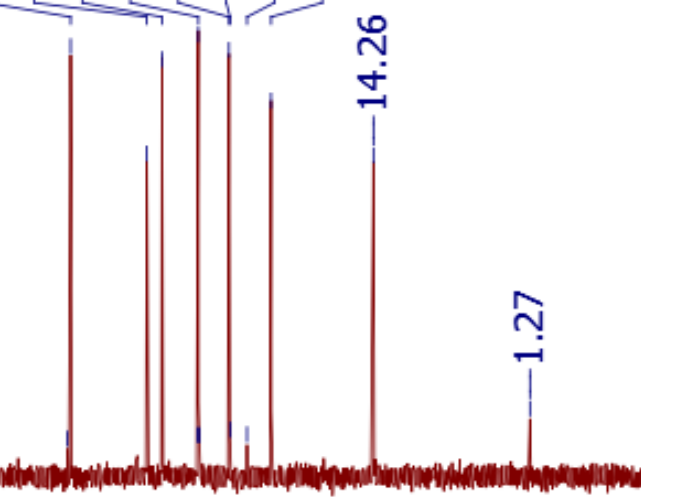

$\begin{array}{lllllllllllllllllllllllll}220 & 210 & 200 & 190 & 180 & 170 & 160 & 150 & 140 & 130 & 120 & \begin{array}{l}110 \\ \mathrm{f} 1(\mathrm{ppm})\end{array} & 100 & 90 & 80 & 70 & 60 & 50 & 40 & 30 & 20 & 10 & 0 & \end{array}$




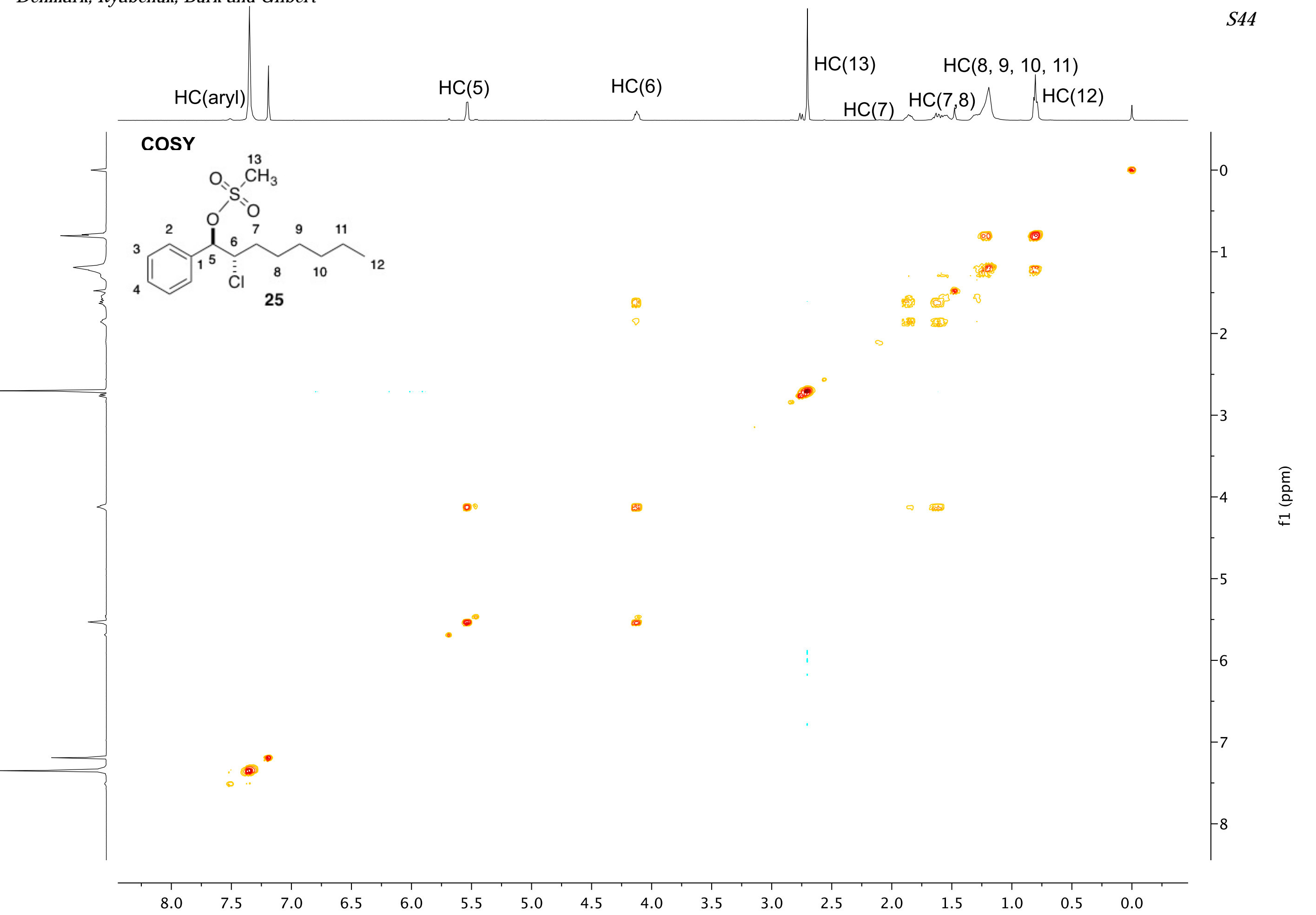




\section{Denmark, Ryabchuk, Burk and Gilbert}






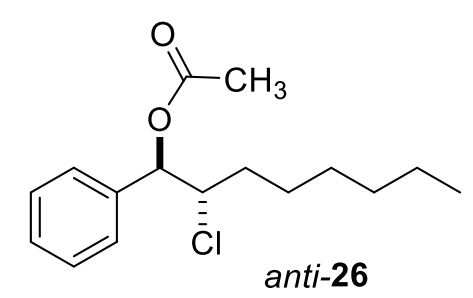

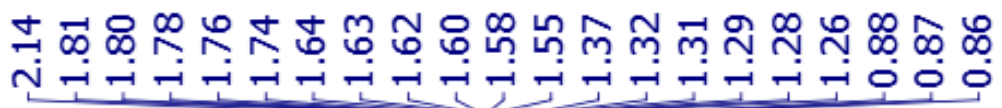

mิ లి

rnon

S $\sigma \infty \varnothing$

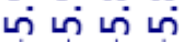

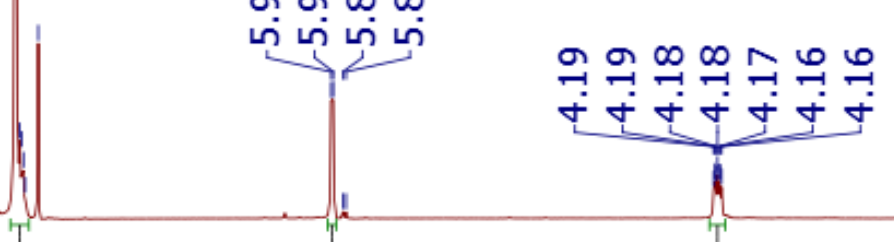

莴

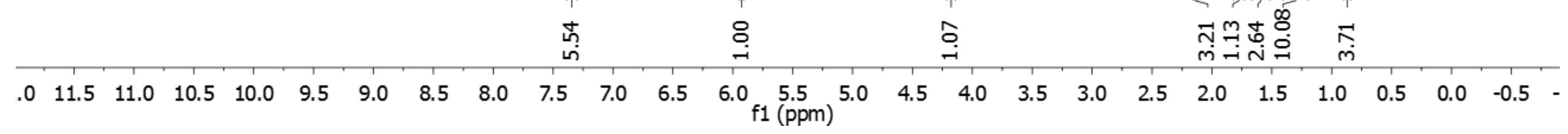






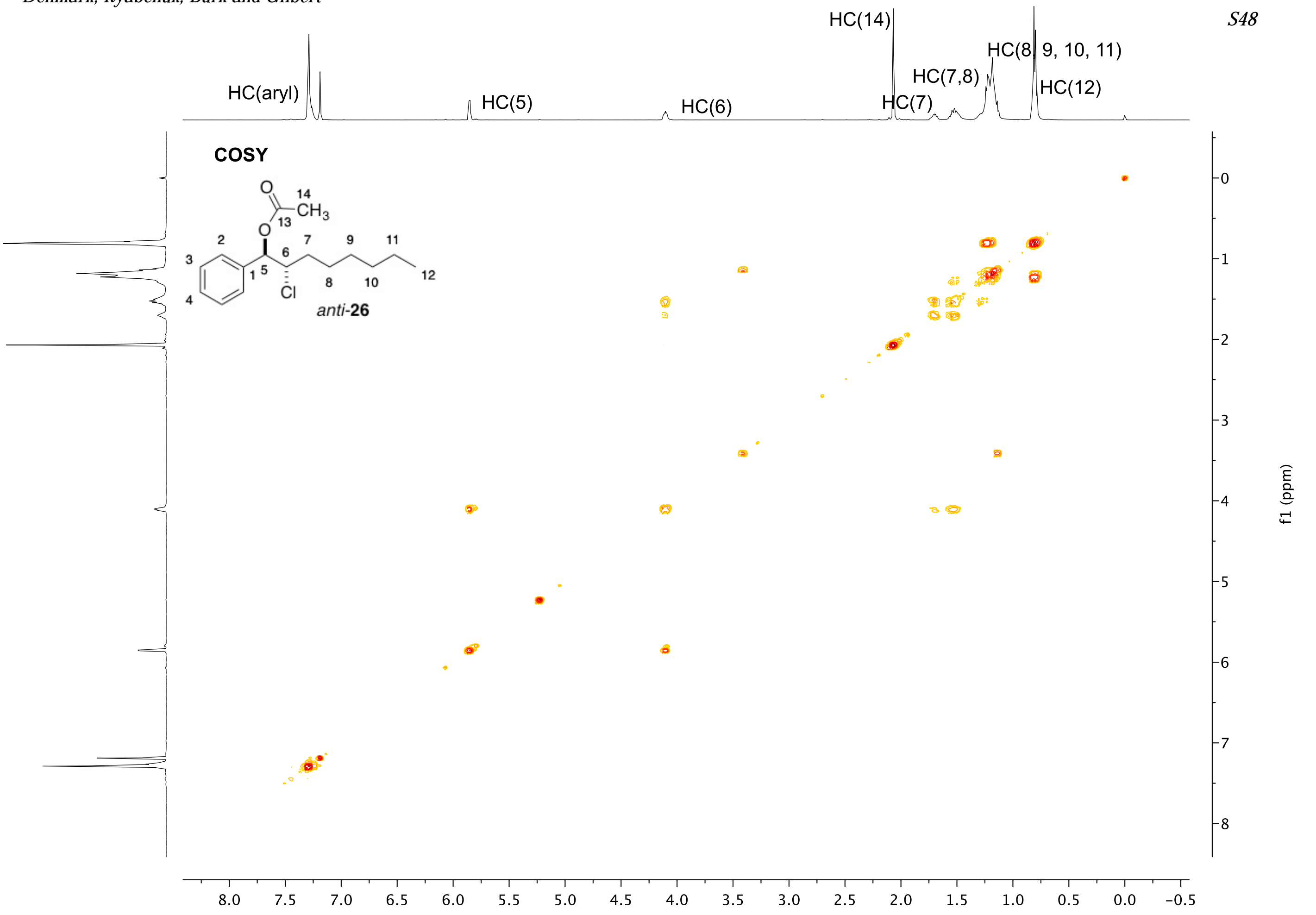




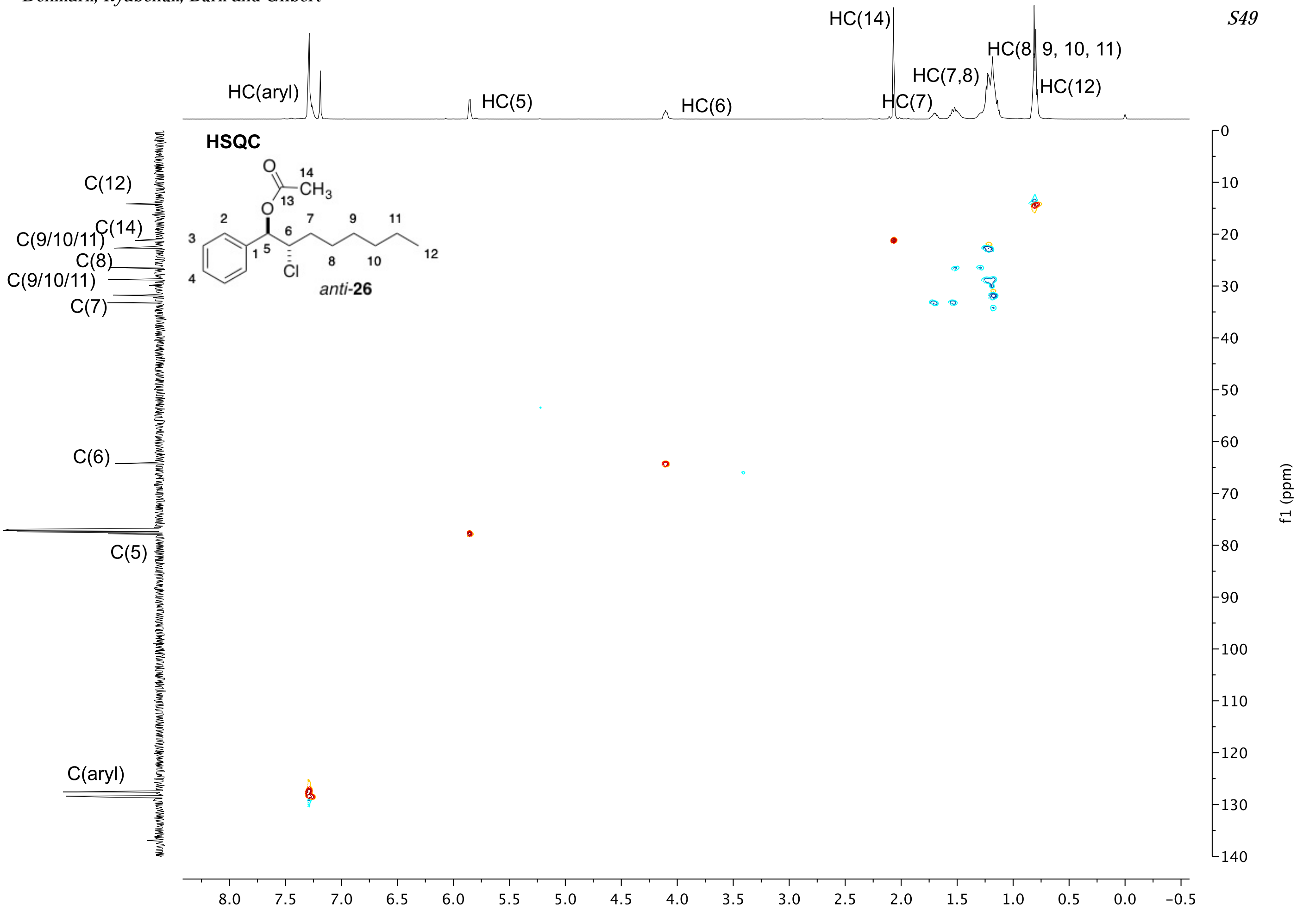


14-56-0min

ANDARD PROTON PARAMETERS

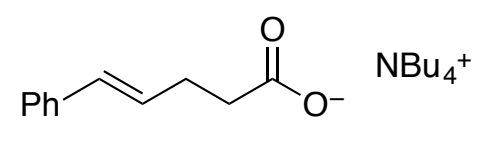

23
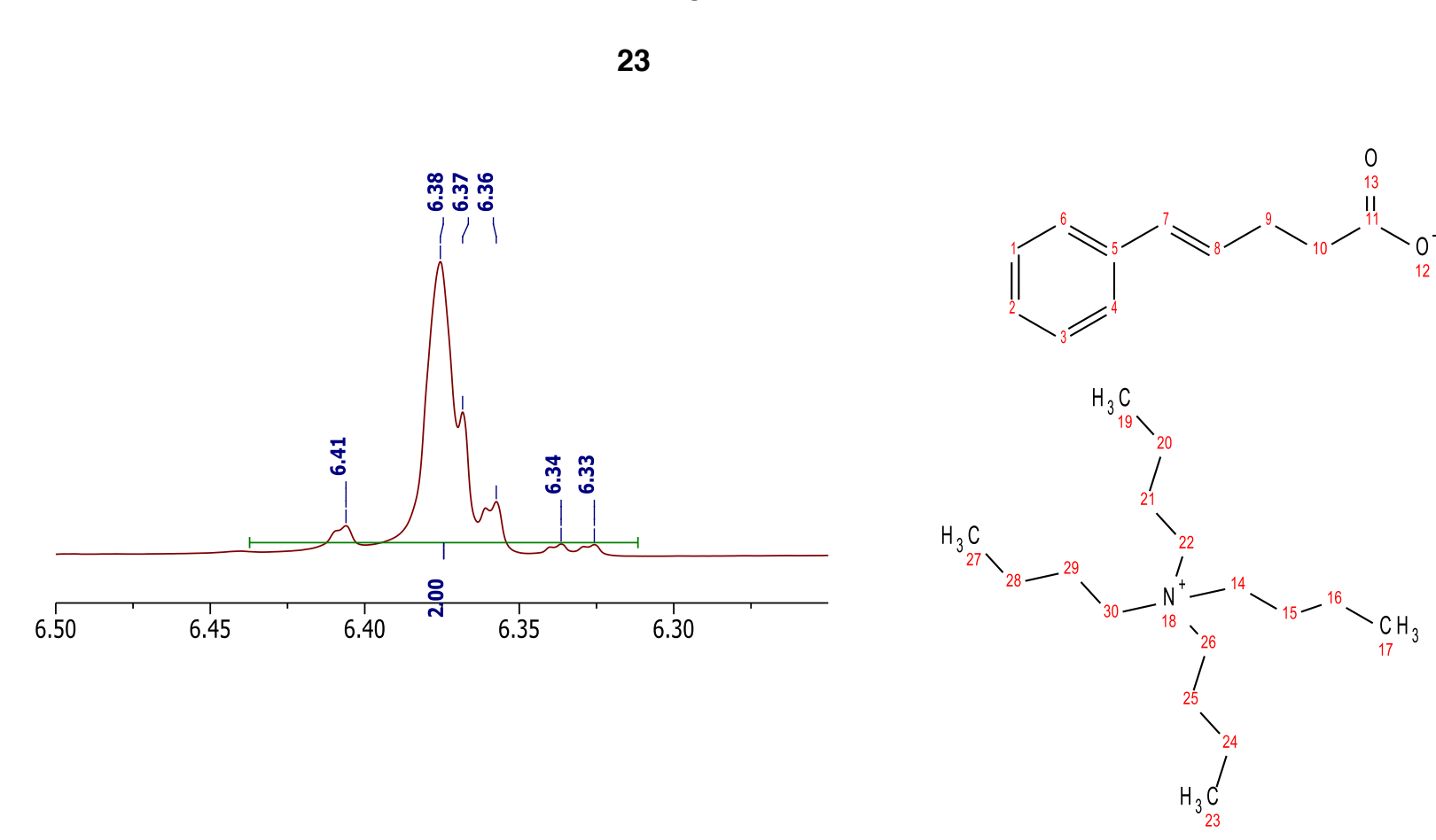

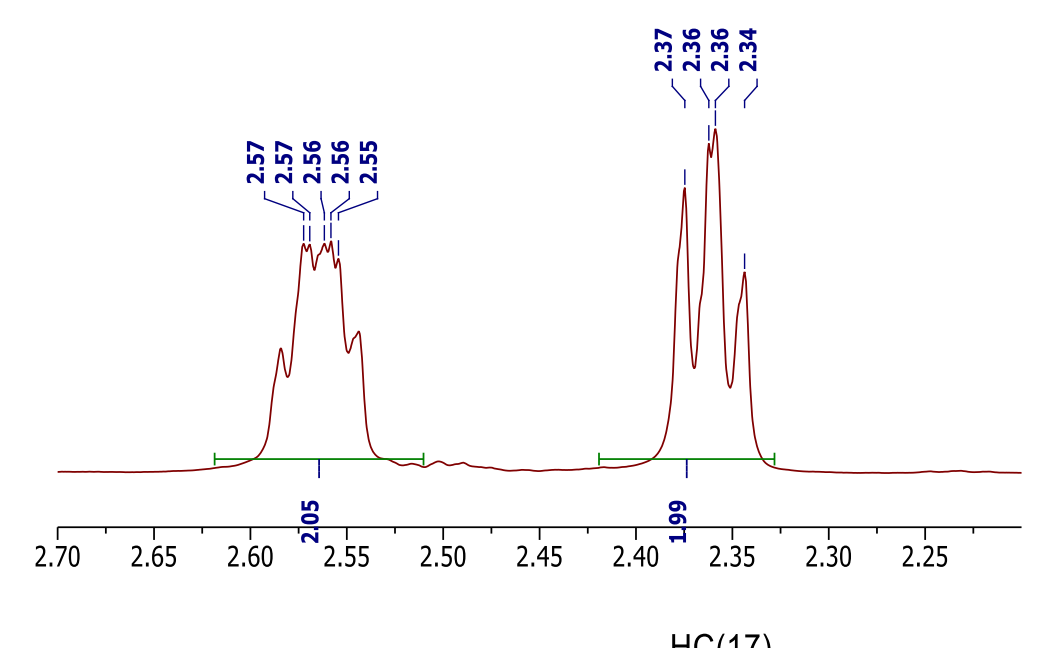

$\mathrm{HC}(17)$

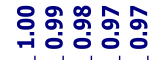

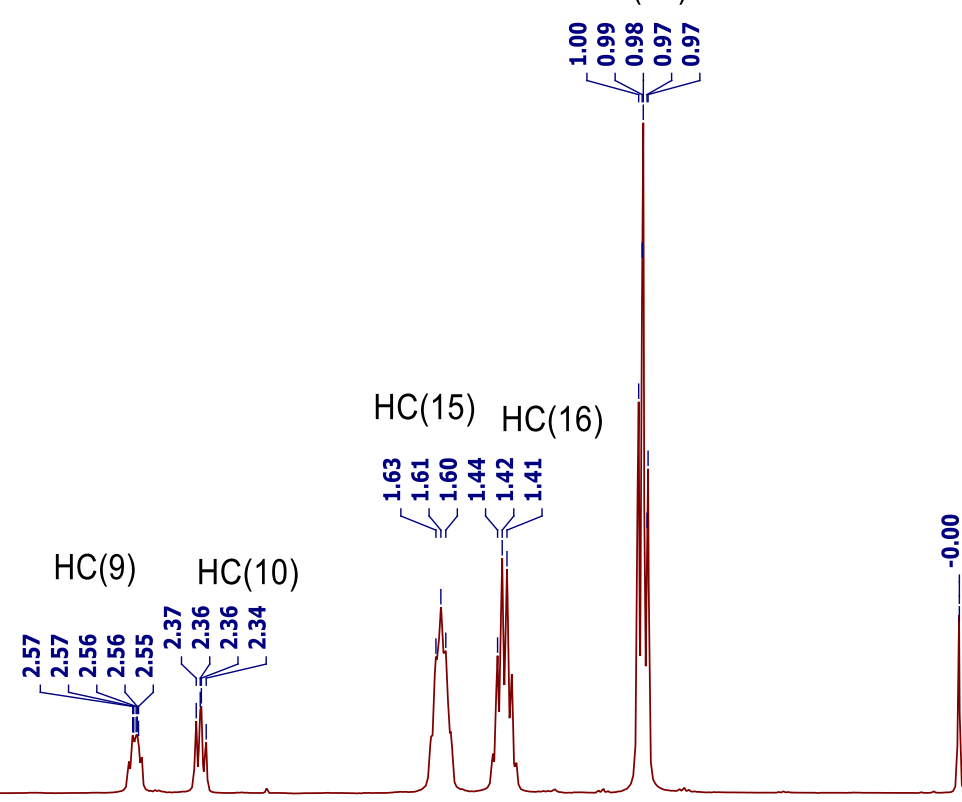

:

$\mathrm{HC}(7)$

$\mathrm{HC}(8)$

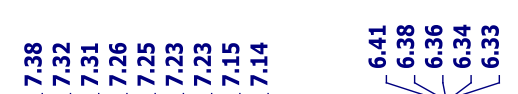

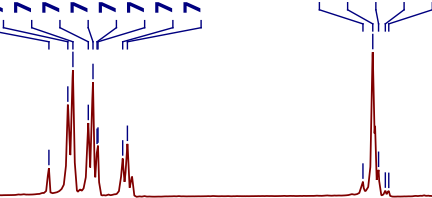

(14)

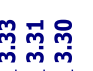

$4 \quad \mathrm{HC}(9) \quad \mathrm{HC}(10)$

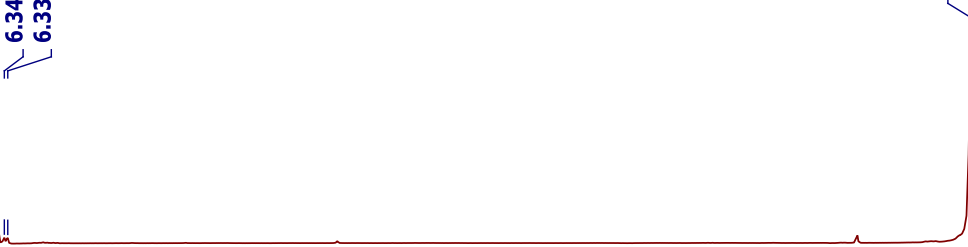

I

ग

$\longmapsto \mapsto$

IT

i




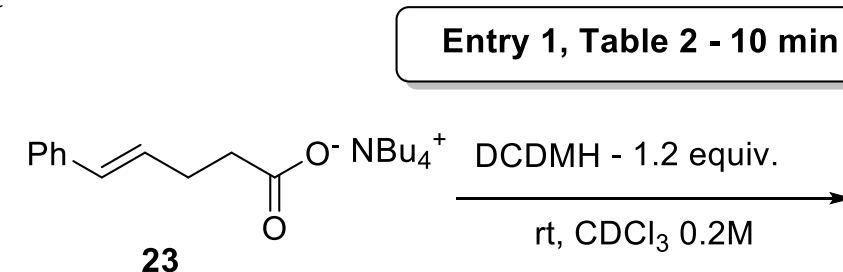

23

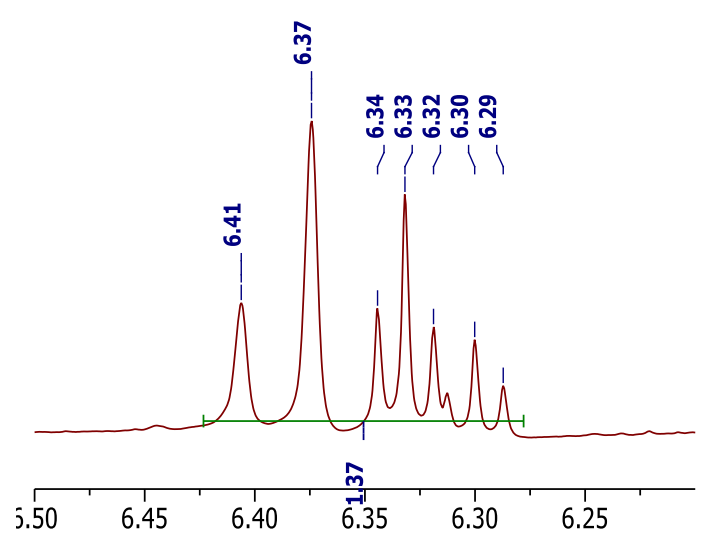

$\mathrm{HC}(14)$

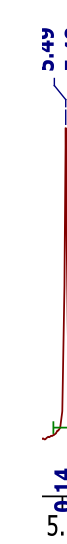

P.
5.5
5
5

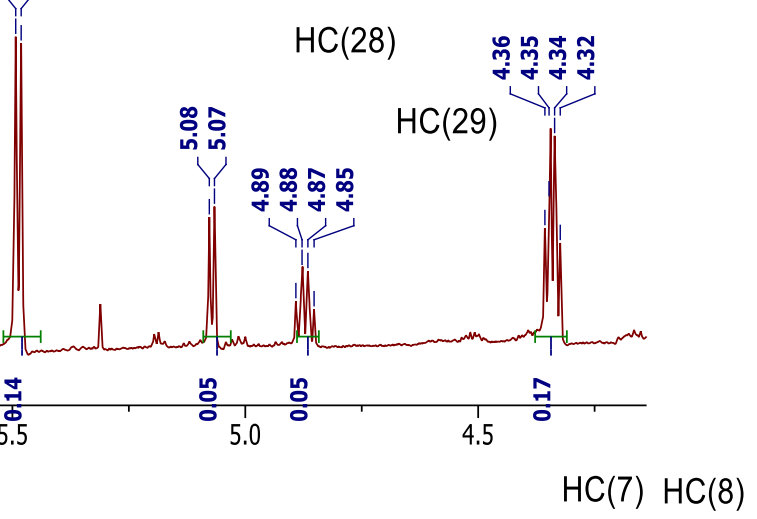

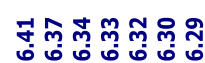

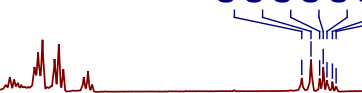

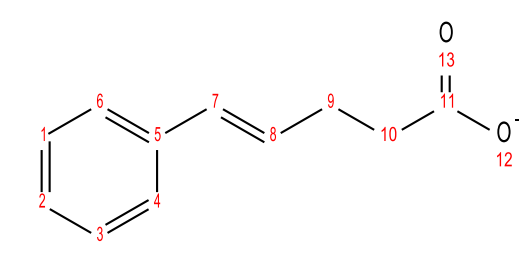
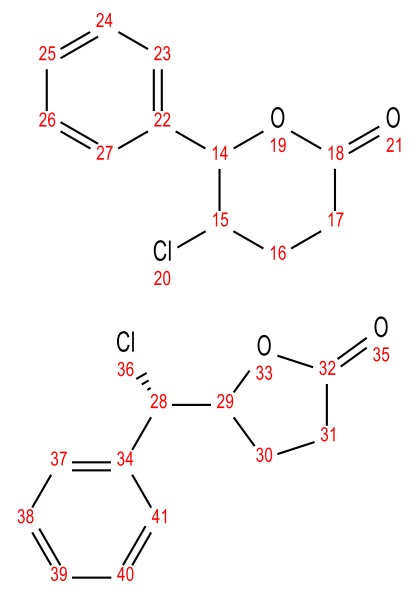

我



Ph

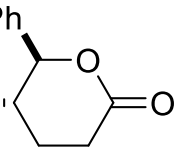

9<smiles>O=C1CCC([C@H](Cl)c2ccccc2)O1</smiles>

$\mathrm{HC}(10)$

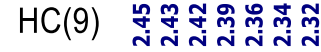

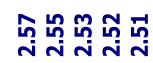

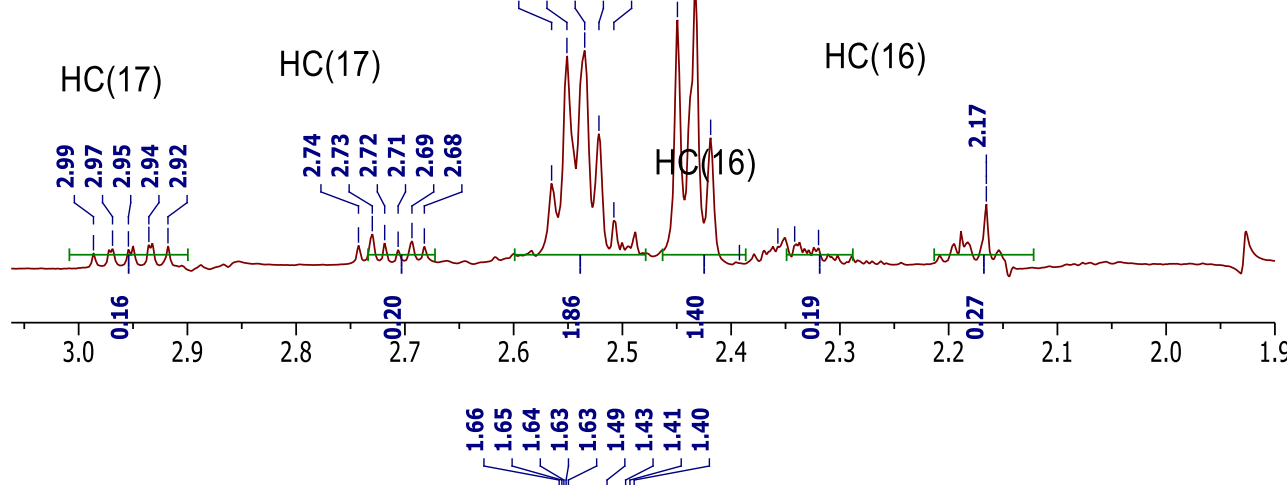

DCDMH

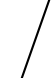

$\mathrm{HC}(10)$

ํํㅇํํำ

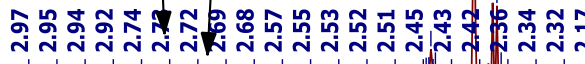

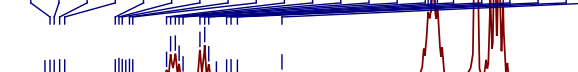

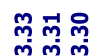

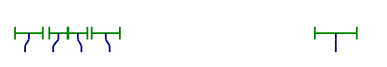

TT T'T 'T

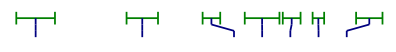

एगत

TI

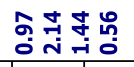

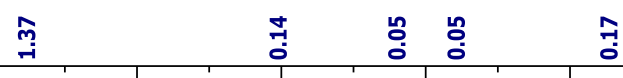

당 \&



$\stackrel{\infty}{\exists}$ 


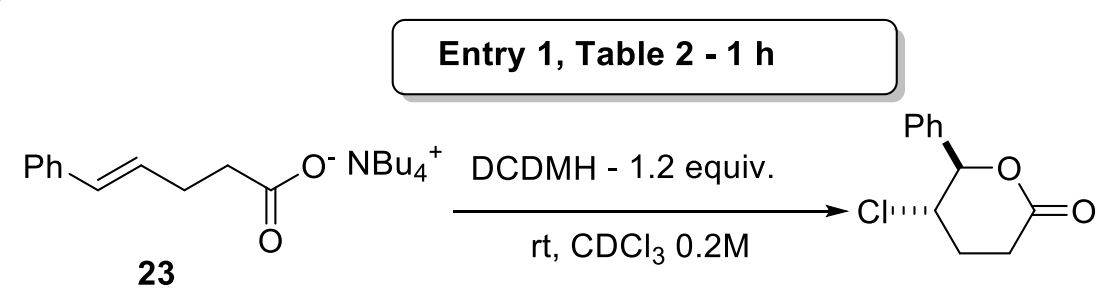

RP4-56-1h-nocat

STANDARD PROTON PARAMETERS

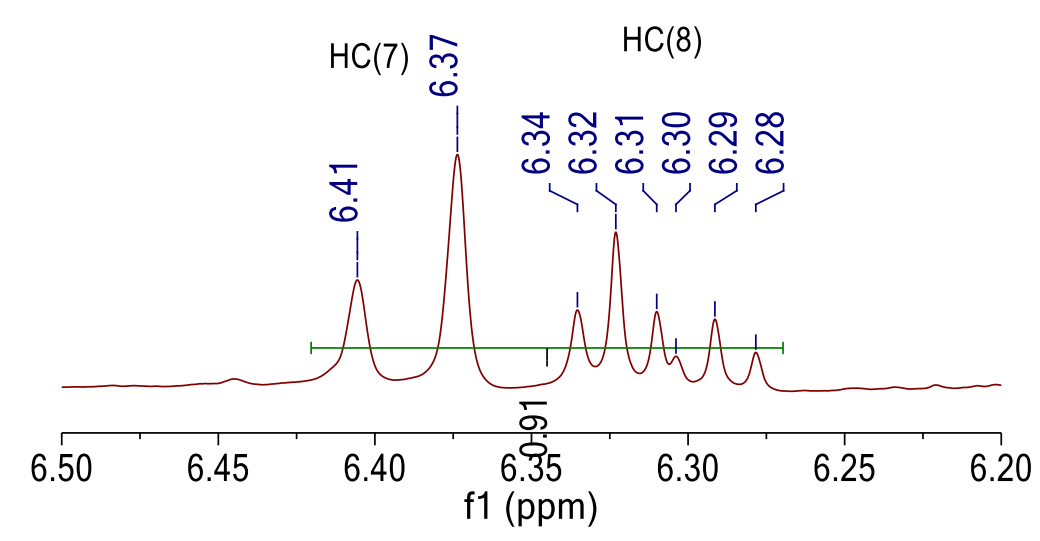

$\mathrm{HC}(14)$

守 守

LC

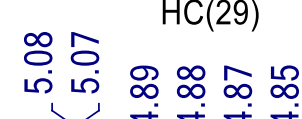

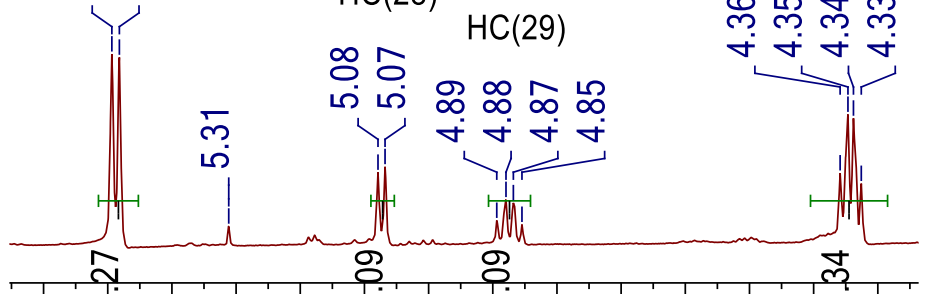

$\begin{array}{lllllllllllllll}5.6 & 5.5 & 5.4 & 5.3 & 5.2 & 5.9 & 5.0 & 4.9 & 4.8 & 4.7 & 4.6 & 4.5 & 4.4 & 4.3\end{array}$

f1 (ppm)
9

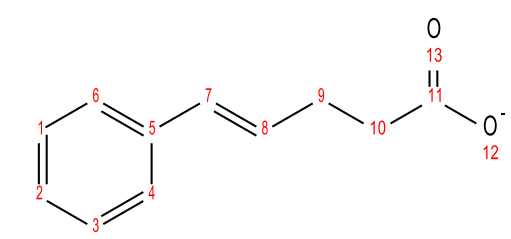

$\overbrace{24}^{\mathrm{Cl}}$

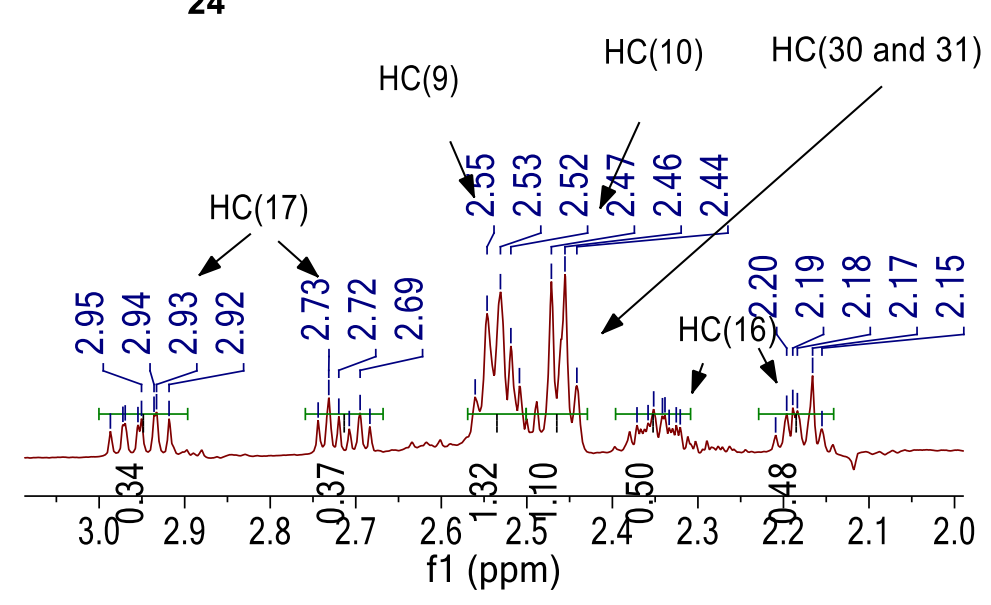

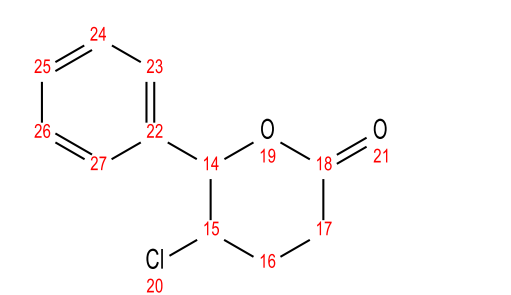


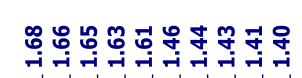

$\mathrm{DCDMH}$

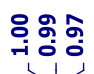

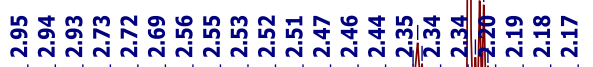
(1)



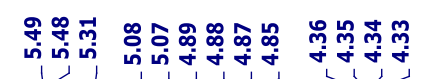
就似

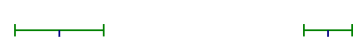

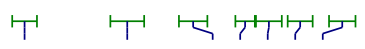
T5"T Tा

के

6.0

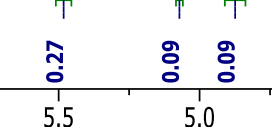

范

4.0

3.5

3.0

2.5

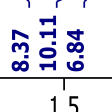
1.0 


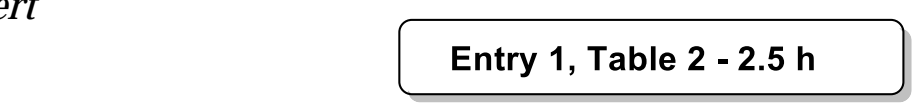

RP4-56-2.5-nocat

STANDARD PROTON PARAMETERS
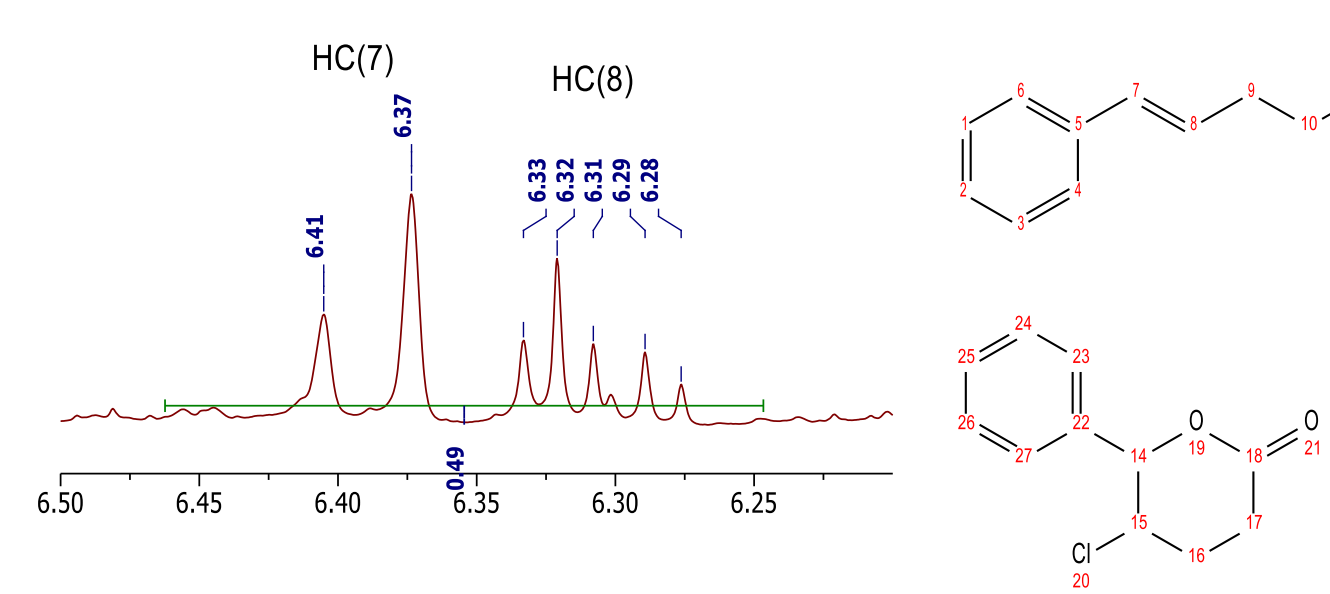

$H C(14)$

$\mathrm{HC}(29)$

赵

\section{我骂高品}



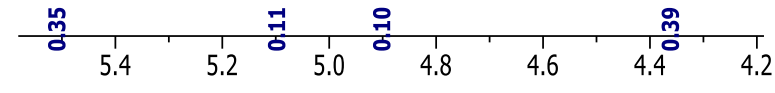

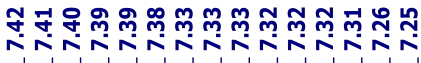

ill

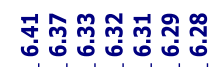

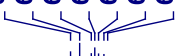

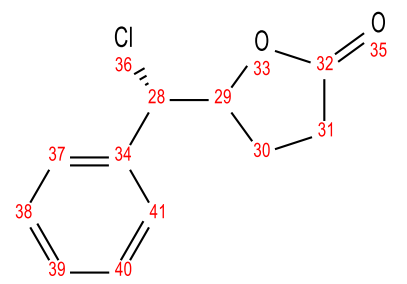



9


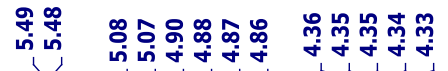

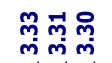



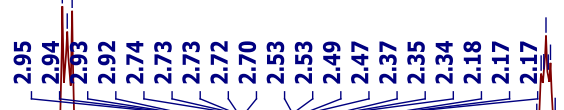<smiles>O=C1CCC([C@H](Cl)c2ccccc2)O1</smiles>

$24 \mathrm{O}$
$\mathrm{HC}(30$ and 31)

มิำก

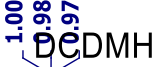






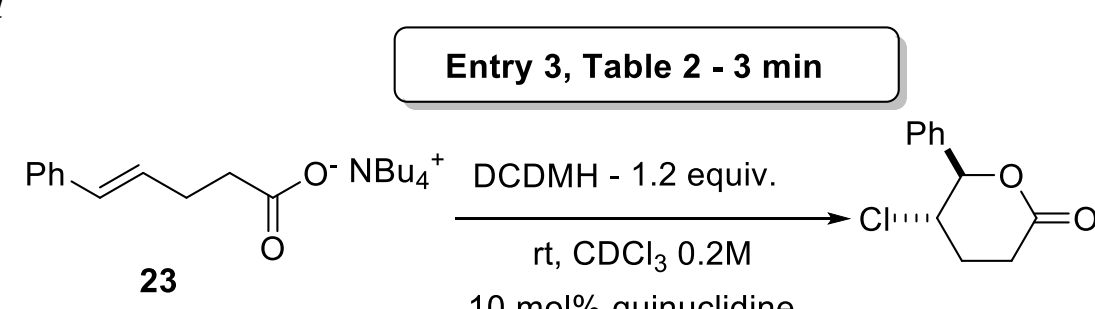

23

$\mathrm{HC}(8)$

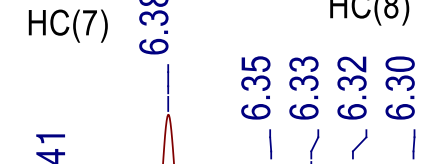

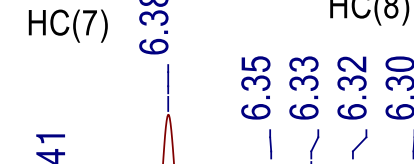

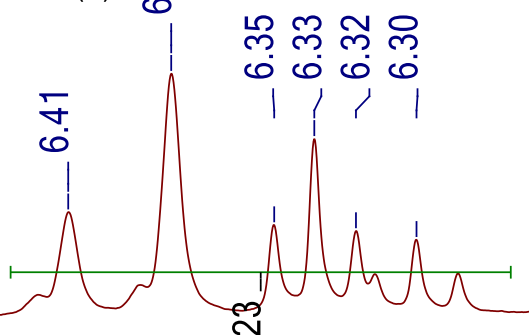

$\stackrel{2}{\pi}$

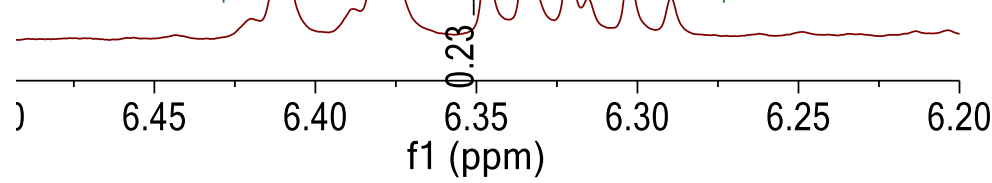

$\mathrm{HC}(14)$

g 守

$\mathrm{HC}(28)$

$\mathrm{HC}(15)$



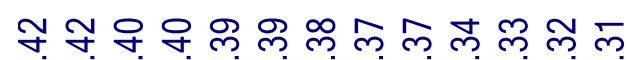



$\infty$
チ

守 俒

రి

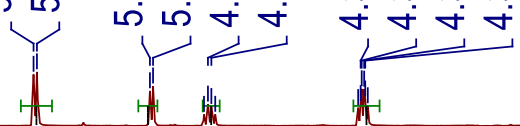

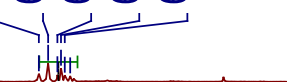

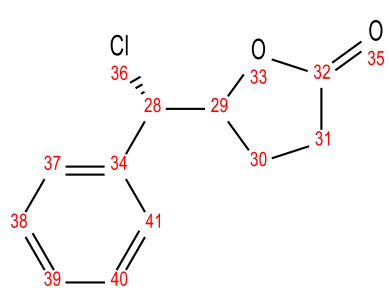

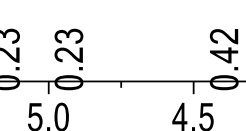

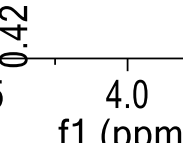

$10 \mathrm{~mol} \%$ quinuclidine
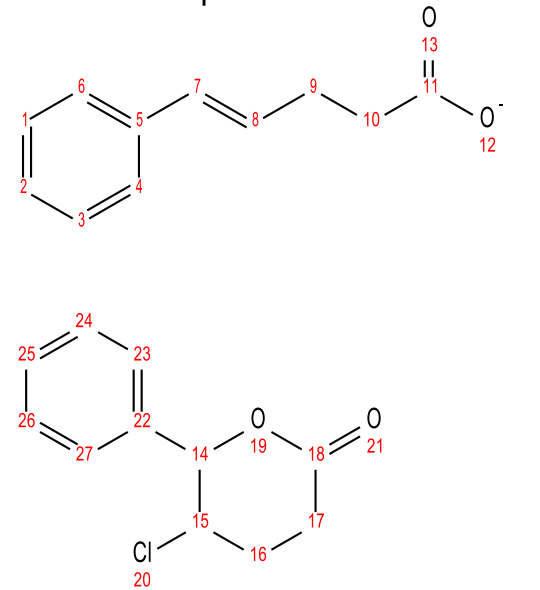

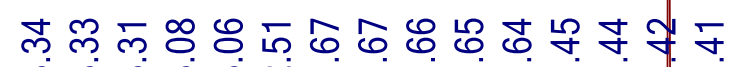

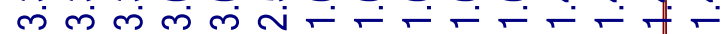

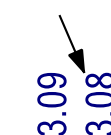<smiles>O=C1CCC(C(Cl)c2ccccc2)O1</smiles>

Quibuclidine

$\mathrm{HC}(9)$

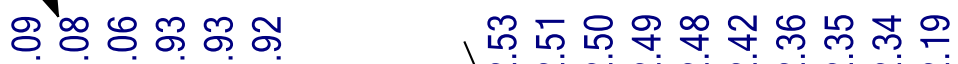
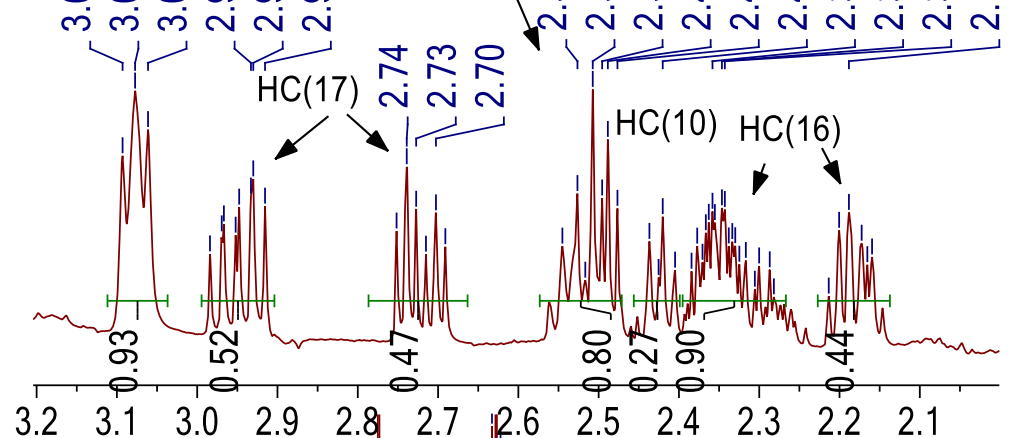

$\begin{array}{llllllllllll}3.2 & 3.1 & 3.0 & 2.9 & 2.8 & 2.7 & 2.6 & 2.5 & 2.4 & 2.3 & 2.2 & 2.1\end{array}$

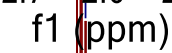

웅

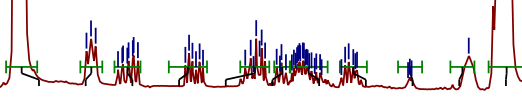
8ㅇํำ

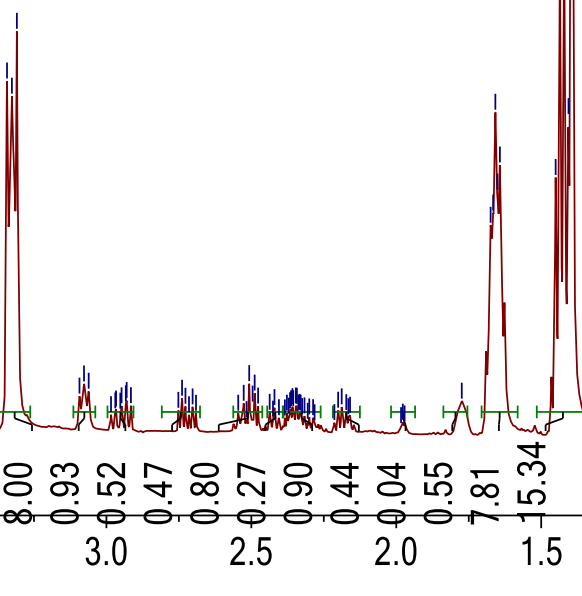

